Feedback underpins organizational learning. To find the highest level of success in learning for change, feedback should be invited, analyzed in the most positive manner possible, and used to impact decision making.

\section{Seeking Feedback on Learning for Change}

\section{By Olivier Serrat}

\section{Learning to Change ...}

The rapidly changing - and, at times, excessively complexnature of development work demands diverse competences from aid agencies such as the Asian Development Bank. In addition to technical knowledge and skills, they include no less than appreciating political economy; building relationships; reading and responding to complex organizational and social predicaments; and increasing capacity to contend with uncertainty, task-compromise, and deal with difference and diversity. The learning challenges that these demands present require the ability to work more reflectively in a turbulent

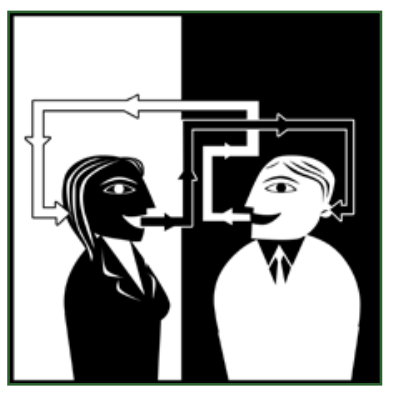
practice environment. There is no alternative: to remain relevant and effective, an organization's rate of learning must be at least equal to-but preferably greater than - the rate of change in the environment.

In 2009, Learning for Change in $A D B^{1}$ was published to help deliver the increased development effectiveness that Strategy 2020, ADB's long-term strategic framework, seeks. It broadly defined a learning organization as a collective undertaking, rooted in action, that builds and improves its own practice by consciously and continually devising

Feedback is the breakfast of champions.

-Ken Blanchard experience. Usefully, it assimilated the manifold dimensions of the learning organization and marked out generic roadblocks to learning. Notably, Learning for Change in $A D B$ specified how action across organization, people, knowledge, and technologythe learning organization model it created - can energize and support individual, team, and cross-functional learning, and in return be enriched by learning.

ADB. 2009. Learning for Change in ADB. Manila. Available: www.adb.org/documents/books/learning-forchange/default.asp 


\section{... With Feedback}

Organizations that neither invite nor cherish feedback from personnel, clients, audiences, and partners are working in a vacuum. Feedback is the answer to their travails. These Knowledge Solutions showcase the details of the internal Learning for Change survey that ADB launched in 2010 to gauge perceptions of competencies to learn for change in ADB.

\section{Box: 2010 Learning for Change Survey}

Purpose and Design. The internal, electronic Learning for Change survey was introduced in 2010 to place an accent on organizational learning in $\mathrm{ADB} .^{2}$ The questionnaire featured 10 positive statements depicting ideal levels of organizational competence across four "pillars" representing four subsystems deemed necessary for organizational learning, namely (i) organization, (ii) people, (iii) knowledge, and (iv) technology (Appendix 1). The perceptions of staff members were captured in absolute confidence using a six-point Likert scale: $1=$ strongly agree, $2=$ agree, $3=$ neutral, $4=$ disagree, $5=$ strongly disagree, $6=$ don't know. The results of the survey provide a baseline for subsequent rounds. ${ }^{3}$

Respondents. A total of 256 staff members from a complement of 2,705 (as of 30 June 2010) responded to the survey from 23 departments (Appendix 2). ${ }^{4}$ The majority (45\%) of the respondents regrouped professional

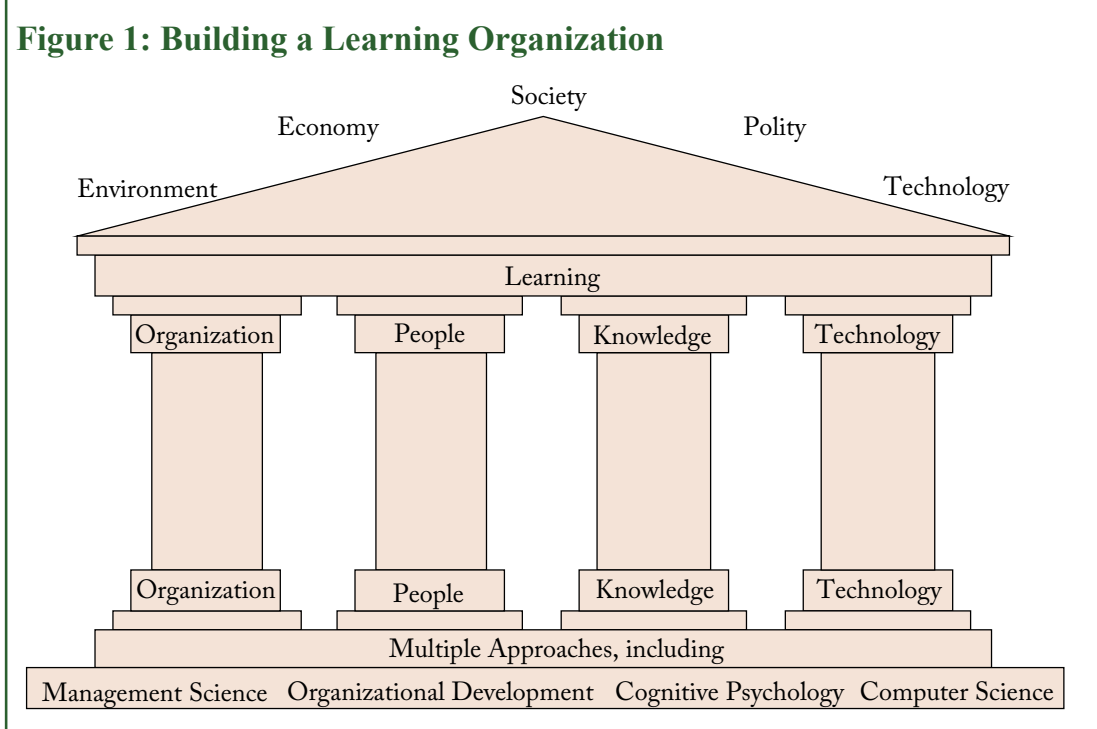

Source: ADB. 2009. Learning for Change in ADB. Manila. Available: www.adb.org/documents/books/ learning-for-change/default.asp

2 The rationale for the learning organization model used in the survey is laid out in ADB. 2009. Learning for Change in ADB. Manila. Available: www.adb.org/documents/books/learning-for-change/default.asp

3 Since 2005, ADB has conducted annual electronic surveys to gauge staff perceptions of knowledge management. Survey findings are benchmarked against eight recognized MAKE (Most Admired Knowledge Enterprises) knowledge performance dimensions: (i) creating and sustaining an enterprise knowledge-driven culture, (ii) developing knowledge workers through senior management leadership, (iii) developing and delivering knowledge-based products/services/solutions, (iv) managing and maximizing the value of enterprise intellectual capital, (v) creating and sustaining an enterprise-wide collaborative knowledge-sharing environment, (vi) creating and sustaining a learning organization, (vii) managing client knowledge to create value and enterprise intellectual capital, and (viii) transforming ADB knowledge to reduce poverty and improve clients' standard of living. Available: www.adb.org/knowledgemanagement/assessment.asp. The results of the 2009 MAKE survey were the most positive to date. However, the number of dimensions the MAKE surveys benchmark is limited and their focus is on knowledge management: the 2010 Learning for Change survey was conducted to introduce a new diagnostic tool that examines organizational learning and deepens understanding of progress toward creating and sustaining a learning organization.

4 This represents a response rate of $9 \%$. The survey sample is considered statistically representative of the total target population. 
staff, the second-largest group comprised administrative staff (38\%), and the remainder (17\%) were national officers (Figure 2).

Across departments, $47 \%$ of the respondents were from the regional departments, ${ }^{5} 12 \%$ from the knowledge departments, ${ }^{6}$ and $41 \%$ from other departments (Figure 3). Departmental response rates varied

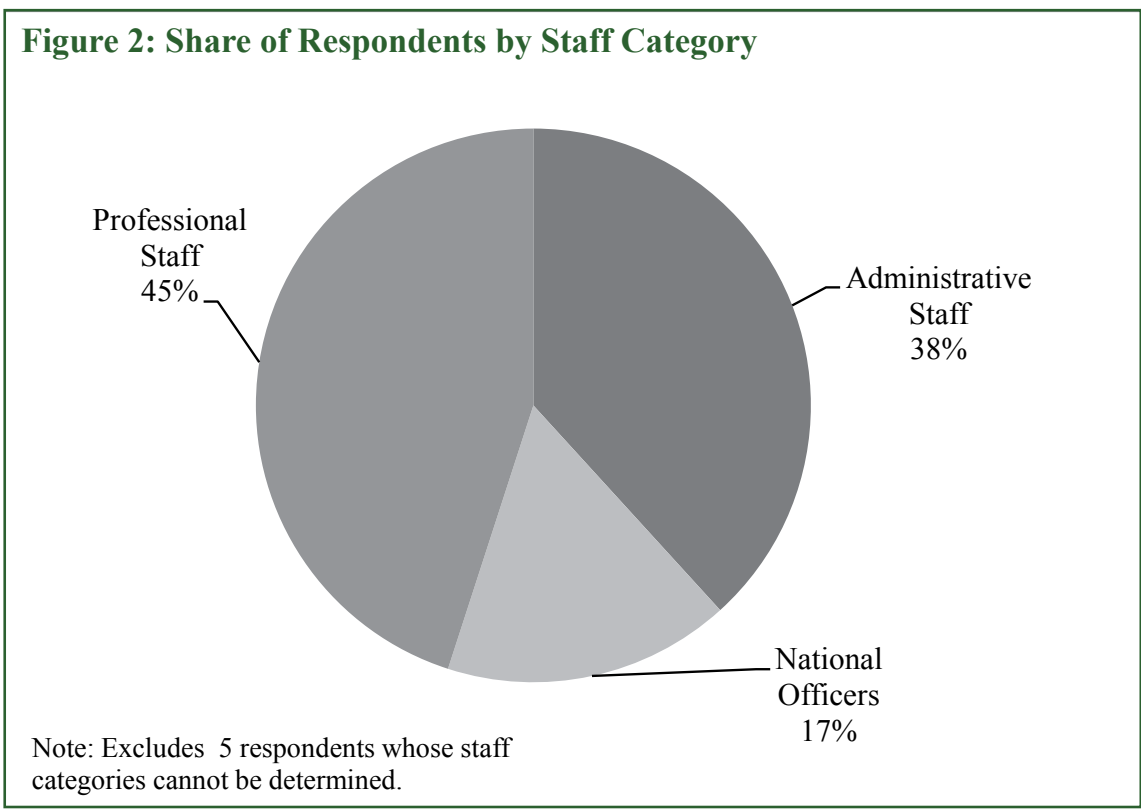

considerably-from $2 \%$ to $75 \%$, with 7 out of the 23 responding departments showing relatively high response rates of $20 \%$ or over.

Overall Results. Feedback from staff members on each statement deserves dedicated attention. However, overall, survey results (Appendixes 3-7) indicate that, among the four subsystems, staff members perceived

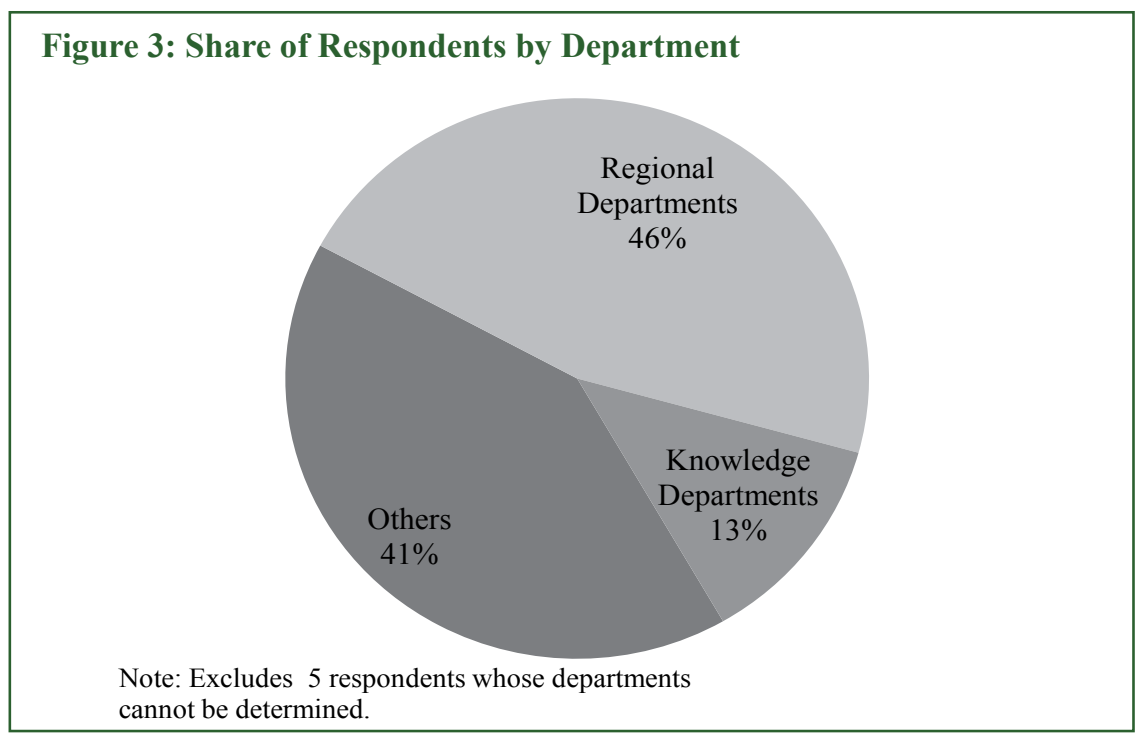

5 The regional departments are the Central and West Asia Department, East Asia Department, Pacific Department, South Asia Department, and Southeast Asia Department.

6 The knowledge departments are the Asian Development Bank Institute, Economics and Research Department, Office of Regional Economic Integration, and Regional and Sustainable Development Department. 
$\mathrm{ADB}$ to be most competent in relation to the technology subsystem; it needs most improvement in the people subsystem. Dropping the "don't know" (or 6) responses and inverting the Likert scale, where 5 is equivalent to "strongly agree" (hence becoming the ideal score) and 1 represents "strongly disagree," the mean score for the responses for all 10 items under the technology subsystem is 3.32 while that for the people subsystem is 3.02 (Figure 4). The organization and knowledge subsystems have mean scores of 3.26 and 3.17 , respectively.

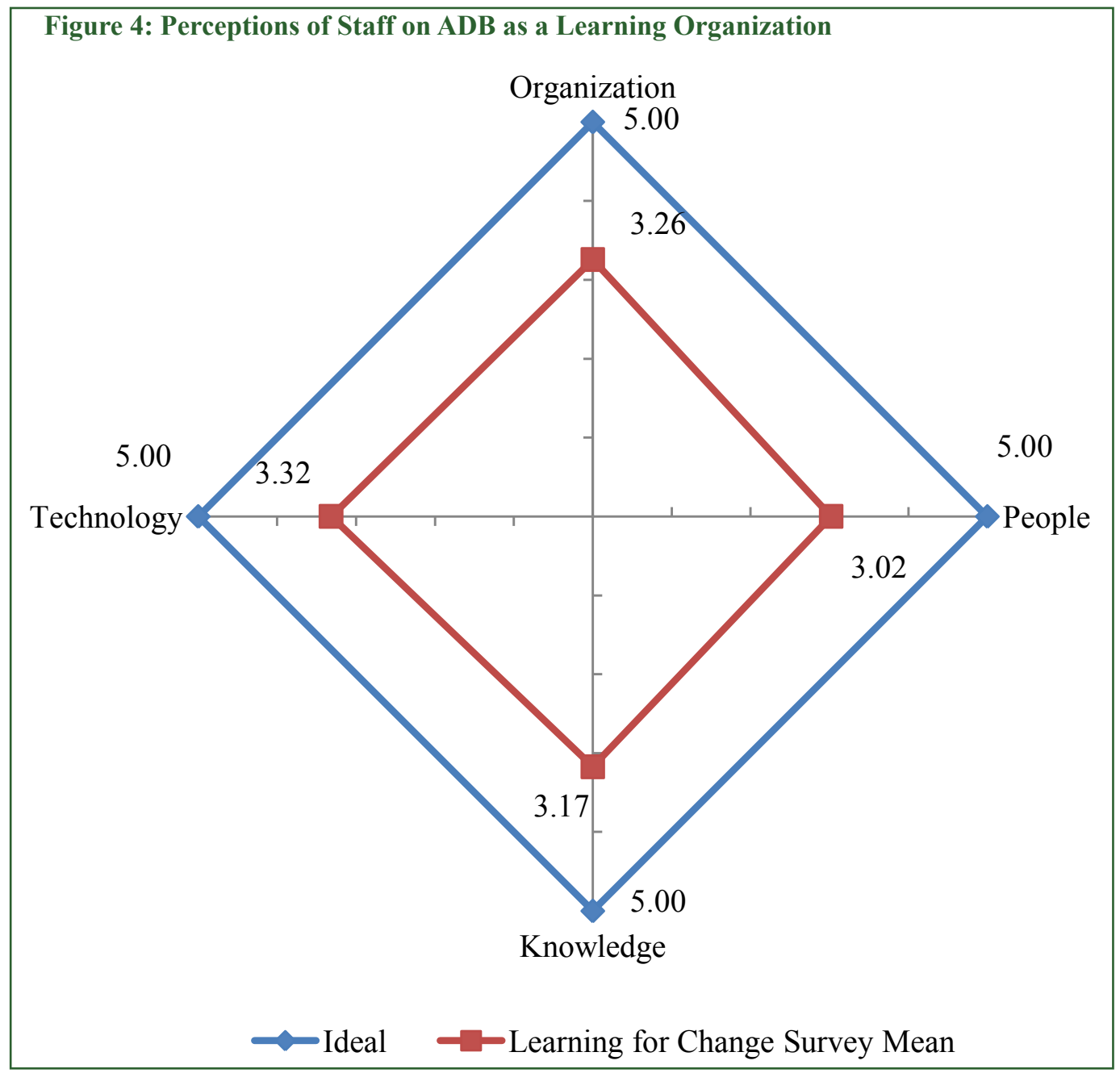

Taking into account the average percentage of respondents who collectively "strongly agree" and "agree" to the 10 statements per subsystem, the rankings of the subsystems are retained. The technology and people subsystems are first and last at 53\% (Table 4) and 38\% (Table 2), respectively. The organization subsystem ranks second at $48 \%$ (Table 1) while the knowledge subsystem is positioned third at $43 \%$ (Table 3 ). 
The Organization Subsystem. Among the 10 statements under the organization subsystem, respondents "strongly agree" and "agree" most with two statements (59\% for each): (i) "there is an inspiring vision for learning and an organizational learning strategy that clearly communicates that learning is critical to organizational success" (statement 1), and (ii) "emergent learning is encouraged by creating opportunities for informal sharing of knowledge and experience" (statement 9). The majority (51\%) also agrees that "leaders take an exemplary leading role in creating and sustaining a supportive learning culture" (statement 2). The highest rate of neutrality (36\%) is toward the statement, "Failures and unintended outcomes are the focus of constructive discussions. When such incidents involve clients, care is taken to protect their reputation" (statement 10). This is also one of two statements for which the highest percentage of "don't know" responses overall (13\%) is found (probably because many respondents would be unable to answer the second part of the statement regarding the protection of client reputation). Finally, there is highest rate of disagreement (34\%) with the statement, "adequate resources are allocated for learning in terms of time, allocation, specialist support staff, budgets for knowledge management infrastructure, formal and informal communities of practice and other value networks, and learning and development programs" (statement 6). Table 1 presents the survey results for the organization subsystem.

Table 1: Perceptions of the Organization System (\%)

\begin{tabular}{|c|c|c|c|c|c|c|c|}
\hline & Statement Subject & $\begin{array}{l}\text { Strongly } \\
\text { Agree }\end{array}$ & Agree & Neutral & Disagree & $\begin{array}{l}\text { Strongly } \\
\text { Disagree }\end{array}$ & $\begin{array}{l}\text { Don't } \\
\text { Know }\end{array}$ \\
\hline 1. & Inspiring vision & 13 & 46 & 18 & 16 & 5 & 2 \\
\hline 2. & Learning culture & 12 & 39 & 23 & 16 & 7 & 2 \\
\hline 3. & $\begin{array}{l}\text { Formal organizational } \\
\text { structure }\end{array}$ & 8 & 38 & 23 & 23 & 7 & 2 \\
\hline 4. & $\begin{array}{l}\text { Informal organizational } \\
\text { structure }\end{array}$ & 4 & 43 & 29 & 14 & 3 & 7 \\
\hline 5. & Communication system & 7 & 41 & 23 & 18 & 6 & 5 \\
\hline 6. & Resources & 5 & 38 & 17 & 26 & 8 & 5 \\
\hline 7. & Approach to learning & 4 & 35 & 34 & 18 & 5 & 4 \\
\hline 8. & Planned learning & 7 & 42 & 25 & 16 & 7 & 4 \\
\hline 9. & Emergent learning & 7 & 52 & 21 & 13 & 4 & 3 \\
\hline & $\begin{array}{l}\text { Failures and unintended } \\
\text { outcomes }\end{array}$ & 3 & 34 & 36 & 9 & 5 & 13 \\
\hline & Average & 7 & 41 & 25 & 17 & 6 & 5 \\
\hline
\end{tabular}

Note: Numbers may not total $100 \%$ because of rounding.

The responses to statement 1 demonstrate a strong sense of communicated vision concerning the importance of learning for ADB's success. This is a critical issue and provides a strong platform for building ADB's organizational learning capacity. The responses to statement 2 concerning leadership's role in creating a supportive learning culture are encouraging. The fact that the number of respondents who "agree" with this statement outnumber those who "disagree" with it by over two to one, with a sizeable share being "neutral", suggests that many ADB leaders are successfully creating a supportive learning culture for their colleagues. It is also significant that statements 1 and 2 have the highest "strongly agree" responses (13\% and $12 \%$, respectively). This indicates a firm belief on the part of those respondents which suggests that there 
may be some examples of particularly good practice to disseminate and learn from. Statement 4 concerning sanctioned informal organizational structures reveals the widest gap in the organization subsystem between those who "strongly agree" (4\%) and those who "agree" (43\%). This suggests the need to examine current areas of good practice and make these examples more widely known within ADB. In statement 7, the noticeable clustering around "neutral" may be explained by a lack of understanding of the terms "planned" and "emergent" when applied to learning and a reluctance to admit to this in the "don't know" category. Statement 10 on "failures and unintended outcomes" reveals the highest level of "neutral" responses (36\%). This may be explained by the limited awareness of many respondents concerning the second half of the statement on the protection of client reputations.

The People Subsystem. Regarding the 10 statements under this subsystem, respondents generally "strongly agree" and "agree" (52\%) with the statement, "leadership (based on the possession of expertise and knowledge) is expected from staff members at all levels in the organizational hierarchy" (statement 10). ADB staff are mostly "neutral" (32\%) about the proposition that "staff members successfully use a wide range of opportunities for individual and team-based learning and development" (statement 7). The highest percentage of respondents (44\%) "strongly disagree" and "disagree" that ADB "uses a wide range of formal and informal rewards and incentives for contributing to organizational learning and knowledge development (e.g., career advancement, increased income, informal peer status, additional time provided for study, and public acknowledgment for innovative contributions made)" (statement 9). Table 2 presents the survey results for the people subsystem.

Table 2: Perceptions of the People Subsystem (\%)

\begin{tabular}{|c|c|c|c|c|c|c|}
\hline Statement Subject & $\begin{array}{l}\text { Strongly } \\
\text { Agree }\end{array}$ & Agree & Neutral & Disagree & $\begin{array}{l}\text { Strongly } \\
\text { Disagree }\end{array}$ & $\begin{array}{l}\text { Don't } \\
\text { Know }\end{array}$ \\
\hline 1. Reflective practitioners & 6 & 44 & 22 & 20 & 7 & 2 \\
\hline $\begin{array}{l}\text { 2. Tools, methods, and } \\
\text { approaches }\end{array}$ & 1 & 33 & 27 & 27 & 6 & 5 \\
\hline 3. Psychological safety and trust & 3 & 31 & 29 & 28 & 6 & 3 \\
\hline 4. Learning communities & 3 & 35 & 30 & 22 & 6 & 5 \\
\hline $\begin{array}{l}\text { 5. New ideas, trends, and } \\
\text { practices }\end{array}$ & 9 & 38 & 27 & 15 & 9 & 2 \\
\hline 6. Developing and retaining staff & 3 & 23 & 29 & 28 & 12 & 5 \\
\hline $\begin{array}{l}\text { 7. Individual and team-based } \\
\text { learning and development }\end{array}$ & 1 & 35 & 32 & 23 & 5 & 4 \\
\hline $\begin{array}{l}\text { 8. Time and performance } \\
\text { management systems }\end{array}$ & 3 & 37 & 23 & 22 & 11 & 4 \\
\hline 9. Rewards and incentives & 2 & 24 & 25 & 29 & 15 & 6 \\
\hline 10. Leadership & 4 & 48 & 22 & 16 & 6 & 4 \\
\hline Average & 3 & 35 & 27 & 23 & 8 & 4 \\
\hline
\end{tabular}

Note: Numbers may not total $100 \%$ because of rounding.

In general, the statements in the people subsystem are likely to represent aspects of organizational learning with which respondents are most familiar. As a result, one would expect to see the highest prevalence of "strongly agree" and "strongly disagree" responses to these statements. What is interesting, however, is that 7 out of the 10 statements cluster noticeably around the "agree"-"neutral"-"disagree" responses with 
these three taking up $78 \%$ for statement $9,80 \%$ for statement $6,87 \%$ of responses for statements 2 and 4 , and a peak of $88 \%$ of responses in statement 3 . The broad balance between "agree"-"neutral"-"disagree" responses suggests a very varied perception of experiences and the potential for significant improvements in this dimension of organizational learning in ADB. Adopting a learning charter might help establish ground rules and common reference points.

Segregating responses by staff category —namely, local staff ${ }^{7}$ and professional staff-it is evident that local staff feel more positively about the people subsystem, with a greater share of them agreeing to more statements than professional staff (Appendix 7). For example, over half of local staff "strongly agree" and "agree" collectively to five statements - namely, statements $1,4,5,8$, and 10-while the highest rate of agreement for professional staff is $44 \%$ for statement 10 only. Further, no professional staff "strongly agree" with statements 2, 6, 7, and 9. Finally, there is a difference of 25 percentage points and above between local and professional staff for those agreeing with statements 2, 4, 7, and 8. It would be interesting to inquire in depth why this is so.

The Knowledge Subsystem. In terms of the knowledge subsystem, the statement to which the highest percentage of respondents "strongly agree" and "agree" (64\%) is "there is widespread recognition that while knowledge is created in the minds of individuals, knowledge development thrives in a rich web of professional networks among individuals" (statement 1 ). The good majority ( $59 \%$ and $51 \%$, respectively) also "strongly agree" and "agree" that in ADB (i) "there are creative opportunities for knowledge to be developed and shared with others by facilitating networks between individuals" (statement 3), and (ii) "the design and delivery of products and services demonstrate how effective the organization is at applying what it has learned about the nature of good practice" (statement 4). ADB staff were found to be largely "neutral" $(32 \%)$ to the statement, "adoption of after-action reviews and retrospects to learn from experience has been successful" (statement 10). Incidentally, this is the other statement (as mentioned in paragraph 6) to which the highest rate (13\%) of "don't know" responses was recorded (explicable, perhaps, by lack of familiarity with the concepts used). On the other hand, respondents most "disagree" and "strongly disagree" (44\%) that "the organization has a resilient organizational memory and is not vulnerable to the loss of important knowledge when staff members move to other jobs in the organization or leave" (statement 8 ). This reveals a significant concern about loss (or potential loss) of organizational memory. This should be of real concern to the Human Resources Division, which provides the "last resort" means of capturing knowledge and expertise from departing staff. However, better means of addressing this would be the introduction of exit interviews in offices and departments and a personal commitment from each staff to consider: "What knowledge and experience should I be passing on to colleagues so that they and ADB gain from my work in case I move on to another job?" Table 3 presents the survey results for the knowledge subsystem.

Table 3: Perceptions of the Knowledge Subsystem (\%)

\begin{tabular}{|c|c|c|c|c|c|c|}
\hline Statement Subject & $\begin{array}{l}\text { Strongly } \\
\text { Agree }\end{array}$ & Agree & Neutral & Disagree & $\begin{array}{l}\text { Strongly } \\
\text { Disagree }\end{array}$ & $\begin{array}{l}\text { Don't } \\
\text { Know }\end{array}$ \\
\hline 1. Professional networks & 9 & 55 & 17 & 9 & 5 & 5 \\
\hline 2. Access & 5 & 42 & 27 & 20 & 4 & 2 \\
\hline $\begin{array}{l}\text { 3. Opportunities for knowledge } \\
\text { development and learning }\end{array}$ & 4 & 55 & 23 & 14 & 3 & 2 \\
\hline 4. Products and services & 4 & 47 & 26 & 11 & 5 & 7 \\
\hline 5. Systems and infrastructure & 2 & 34 & 24 & 27 & 8 & 4 \\
\hline
\end{tabular}


Table 3 Continued

\begin{tabular}{llccccc}
\hline 6. Evaluations & 4 & 30 & 28 & 20 & 7 & 11 \\
7. Peer assists & 3 & 38 & 29 & 18 & 4 & 7 \\
$\begin{array}{l}\text { 8. Organizational memory } \\
\text { 9. Tacit knowledge }\end{array}$ & 3 & 27 & 21 & 32 & 12 & 5 \\
$\begin{array}{l}\text { 10. After-action reviews and } \\
\text { retrospects }\end{array}$ & 2 & 35 & 31 & 20 & 4 & 9 \\
$\quad$ Average & 2 & 30 & 32 & 19 & 4 & 13 \\
\hline
\end{tabular}

Note: Numbers may not total $100 \%$ because of rounding.

The balanced responses to statement 5 suggest that further investigation would be fruitful here to examine what systems and infrastructure for knowledge management need to be developed, better understood, or made more effective. The responses to statement 6 reveal a very diverse range of views. It is a complex statement that would benefit from further investigation.

The Technology Subsystem. Under the technology subsystem, 74\% "strongly agree" and "agree" that "information and communication technologies are successfully used to keep people informed and aware of corporate developments" (statement 4). Further, more than half of the respondents believe in the following statements: (i) "There is a thorough and shared understanding of the value of information and communication technologies for knowledge management and learning" (statement 1,54\%), (ii) "Information and communication technologies facilitate but do not drive or constrain knowledge management and learning in the organization" (statement 2,63\%), (iii) "Information and communication technologies are successfully used to create and sustain learning communities" (statement 3,52\%), and (iv) "Creative use of information and communication technologies is high. At least five of the following have been successfully adopted: shared document drives, intranet pages, online communities and networks, wikis, and other means of collaborative document production, blogging, online storytelling, lessons learned databases, staff profile pages, online webinars, podcasts, and social network mapping" (statement 9, 54\%). The most "neutral" responses are found in the statement, "information and communication technologies are successfully used to enable people to identify internal sources of expertise" (statement 8 ). The highest percentage of respondents (although only 26\%) "strongly disagree" and "disagree" that "sufficient opportunities are provided for staff members to learn how to make use of available information and communication technologies for learning and sharing" (statement 10). Table 4 presents the survey results for the technology subsystem.

Table 4: Perceptions of the Technology Subsystem (\%)

\begin{tabular}{llccccc}
\hline \multicolumn{1}{c}{ Statement Subject } & $\begin{array}{c}\text { Strongly } \\
\text { Agree }\end{array}$ & Agree & Neutral & Disagree & $\begin{array}{c}\text { Strongly } \\
\text { Disagree }\end{array}$ & $\begin{array}{c}\text { Don't } \\
\text { Know }\end{array}$ \\
\hline $\begin{array}{l}\text { 1. ICTs for knowledge } \\
\text { management and learning }\end{array}$ & 7 & 47 & 26 & 10 & 6 & 4 \\
2. ICTs as facilitator & 6 & 57 & 24 & 9 & 2 & 3 \\
3. Learning communities & 4 & 47 & 25 & 17 & 4 & 3 \\
4. Corporate developments & 8 & 66 & 16 & 6 & 3 & 1 \\
\hline 5. Connections & 4 & 45 & 27 & 13 & 3 & 7
\end{tabular}




\section{Seeking Feedback on Learning for Change}

Table 4 Continued

\begin{tabular}{llccccc}
\hline 6. Innovation and creativity & 4 & 38 & 29 & 18 & 6 & 5 \\
7. Good practices & 4 & 44 & 30 & 15 & 3 & 4 \\
8. Internal sources of expertise & 4 & 38 & 31 & 17 & 5 & 5 \\
9. Creative use & 7 & 46 & 21 & 17 & 3 & 4 \\
10. Opportunities & 5 & 43 & 23 & 19 & 7 & 3 \\
\multicolumn{1}{c}{ Average } & $\mathbf{5}$ & $\mathbf{4 7}$ & $\mathbf{2 5}$ & $\mathbf{1 4}$ & $\mathbf{4}$ & $\mathbf{4}$ \\
\hline
\end{tabular}

ICT = information and technology.

Note: Numbers may not total $100 \%$ because of rounding.

The use of technology for knowledge management and organizational learning seems to emerge as a success story in most responses. It would be interesting to understand in depth why this is so. Positive perceptions may owe in part because the uptake and use of technology in ADB does not require the support of managers or the creation of a supportive learning environment in one's team - one can use the technology if it is there and one knows how. The responses to statement 3 represent a very positive assessment of the contribution of technology to learning communities. Statement 4 shows a very significant recognition by respondents of the value of technology in keeping them informed of corporate developments. While this may not in itself lead to improved organizational learning, personnel who are aware of their place in the wider organization are generally considered to be more likely to contribute their knowledge for its collective good. The responses to statement 8 suggest a need for greater use of technology for internal peer support. Peer assists require an understanding of where expertise resides (not only in terms of current roles and responsibilities but also in light of previous experience). Staff profile pages surely have a role to play.

Subsystem Comparison. The largest proportion of respondents (74\%) "strongly agree" and "agree" that "ADB has made successful use of information and communication technologies to keep people informed and aware of corporate developments" (technology subsystem, statement 4), while the highest rate of disagreement $(44 \%)$ is with the statement that ADB has a "resilient organizational memory and is not vulnerable to the loss of important knowledge when staff members move to other jobs in the organization or leave" (knowledge subsystem, statement 8).

Three statements pertaining to actions taken by ADB ex-post (e.g., evaluations, adoption of after-action reviews and retrospects) consistently generated relatively high frequencies of "don't know" responses. To wit, these statements are (i) "Failures and unintended outcomes are the focus of constructive discussions leading to new approaches. When such incidents involve clients, care is taken to protect their reputation" (organization subsystem, statement 10,13\%); (ii) "Evaluations are carefully designed with learning (as well as accountability) in mind. Systems ensure that the outputs of internal and independent evaluations are made widely available; carefully examined; and used to influence decision making and planning, question orthodox thinking, and trigger creativity and innovation" (knowledge subsystem, statement 6, 11\%); and (iii) "Adoption of after-action reviews and retrospects to learn from experience has been successful" (knowledge subsystem, statement 10,13\%). This reflects minimal awareness of existing policies or the lack thereof.

Concluding Remarks. The survey response rate of $9 \%$, given likely survey fatigue in ADB, is acceptable if not robust and compares reasonably with what is usually considered good for an online survey (10\%). What is very positive are the high response rates from some departments: these demonstrate what is possible when both participant interest and management encouragement are present. The survey mean scores per subsystem are all above 3 (the score that represents "neutral"), which indicates a somewhat favorable yet uncertain view of ADB's capacities, barring exceptions. It is worth remembering that, using a five-point 
Likert scale, to reach a mean score of 4 would require a significant number of "strongly agree" and "agree" responses to balance "neutral", "disagree", and "strongly disagree" feedback so any organization is highly unlikely to achieve a mean score of 4 , let alone the ideal score of 5. This needs to be emphasized in any interpretation of results. In these circumstances, indicators such as the percentage of "strongly agree" and "strongly disagree" responses become significant. Moreover, one should bear in mind that mean scores can obscure significant differences in distributions of responses between statements.

Organizations do not change - the people in them change, and then change their organization. Surveys provide the starting point for effective interventions. On organizational learning, ADB now has a baseline against which to gauge perception of progress, noting that cultural change can take time to anchor. Since the value of any survey increases considerably when there are two or more data sets to compare, therefore, it is recommended that the survey be repeated, perhaps annually, primarily for purposes of organizational learning, not performance measurement. ADB should also ponder what is likely to encourage higher response rates: communicating key findings from the survey; ${ }^{8}$ involving staff in office- and department-led improvements plans to secure buy-in and build lessons into systems, the principal recommendation from the meeting of 3 September 2010 with ADB's knowledge management coordinators; ; sharing evidence that the survey has led to actions being taken, ${ }^{10}$ and requesting management to both take part and encourage personnel to participate in future surveys, thereby enabling deeper analysis at office and departmental levels. ${ }^{11}$

Last but not least, staff are invited to refer to the Knowledge Solutions series ${ }^{12}$ that was conceptualized and launched in support of Learning for Change in $A D B$. The Knowledge Management Center, in collaboration with the Staff Development and Benefits Division, has also formulated the Knowledge Management and Learning Series, ${ }^{13}$ a training program designed to help strengthen staff skills in learning from experience, individually and collectively, and thereby sharpen ADB's focus on knowledge solutions as one driver of change under Strategy 2020.14

8 On 3 September 2010, the Knowledge Management Center shared and discussed the key findings of the 2010 Learning for Change Survey at a meeting of ADB's knowledge management coordinators. (Three resident missions took part.) The meeting helped validate survey results and provided grassroots suggestions for next steps. These might include self-assessments, task analyses, desktop meetings, awareness raising, learning and development, and behavioral reinforcement.

$9 \quad$ Even if each must be involved in knowledge sharing and learning, individual staff typically feel no responsibility and usually do not hold themselves accountable for that.

10 Conducting a survey without intent to change sends the wrong message and can even do harm. The problems of the workplace are not created by what we do but by what we fail to do.

11 To have credibility, leaders must "walk the talk" of organizational change. (Their failure to do so is one of the most common complaints of personnel.) The majority of staff will espouse the corporate values leaders propound if they perceive these to be what upper management truly wants. Importantly, one cannot overcommunicate vision and values. Culture is resilient and hard to change: people will revert to old habits if they are not steered by leadership. Its role is to create positive consequences for positive performance.

12 See ADB. 2008-. Knowledge Solutions. Manila. Available www.adb.org/knowledgesolutions/. The Knowledge Solutions are handy, quick reference guides to tools, methods, and approaches focusing on five areas of competence: (i) strategy development, (ii) management techniques, (iii) collaboration mechanisms, (iv) knowledge sharing and learning, and (v) knowledge capture and storage.

13 The training program comprises 1-2 day courses on Reflective Practice, Learning in Teams, and Learning from Evaluation. The courses are interlinked to deliver a holistic response to the specific needs staff face in their understanding and application of knowledge management and learning. A second round of the courses will be offered in September 2010 and there are plans to introduce courses on Learning Leaders and Learning in Partnerships in 2011.

14 In parallel, the Knowledge Management Center offers 1-hour Learning for Change Primers to raise in-house awareness of and capacity in the areas of (i) Leveraging Knowledge with ICT, (ii) Communities of Practice: Passing the Fitness Test, (iii) Understanding Knowledge Management and Learning Essentials, (iv) Managing Knowledge at Work, (v) Building a Learning Organization, and (vi) Designing Knowledge Partnerships Better. They are available at www.adb.org/knowledge-management/presentations.asp, 


\section{Seeking Feedback on Learning for Change}

Appendix 1: Seeking Feedback on Learning for Change

\section{Organization}

1) There is an inspiring vision for learning and an organizational learning strategy that clearly communicates that learning is critical to organizational success.

2) Leaders take an exemplary leading role in creating and sustaining a supportive learning culture.

3) The formal organizational structure facilitates learning, adaptation, and change.

4) Sanctioned informal organizational structures enable and encourage learning across formal structural boundaries.

5) Good use is made of communication systems to facilitate the lateral transfer of information and knowledge and to minimize the development of "silos".

6) Adequate resources are allocated for learning in terms of time, allocation, specialist support staff, budgets for knowledge management infrastructure, formal and informal communities of practice and other value networks, and learning and development programs.

7) A balanced approach to learning that recognizes the importance of both planned and emergent learning is taken.

8) Planned learning is addressed through the careful design of strategy, structure, systems, procedures, and plans.

9) Emergent learning is encouraged by creating opportunities for informal sharing of knowledge and experience.

10) Failures and unintended outcomes are the focus of constructive discussions leading to new approaches. When such incidents involve clients, care is taken to protect their reputation.

\section{People}

1) Staff members are required to be reflective practitioners to reflect on their experience, develop experience-based theories of change, continuously test these in practice with colleagues, and use their understanding and initiative to contribute to knowledge development.

2) All staff members make frequent use of a range of tools, methods, and approaches for learning and collaborating with others.

3) Staff members experience a high level of psychological safety and trust; they can rely on colleagues and are not exposed to unfair negative criticism.

4) Teams operate as learning communities in which success and unexpected outcomes are analyzed and in which sensitively expressed dissent, conflict, and debate are encouraged as positive sources of learning.

5) Staff members are encouraged to look outside the organization for new ideas, trends, and practices and to share what they learn with colleagues.

6) Equal attention is paid to developing and retaining staff members at all levels.

7) Staff members successfully use a wide range of opportunities for individual and team-based learning and development.

8) Time and effort spent by staff members on learning and knowledge development are recognized as core activities in the organization's time and performance management systems.

9) A wide range of formal and informal rewards and incentives for contributing to organizational learning and knowledge development is used (e.g., career advancement, increased income, informal peer status, additional time provided for study, and public acknowledgment for innovative contributions made).

10)Leadership (based on the possession of expertise and knowledge) is expected from staff members at all levels in the organizational hierarchy.

\section{Knowledge}

1) There is widespread recognition that while knowledge is created in the minds of individuals, knowledge development thrives in a rich web of professional networks among individuals. 
Seeking Feedback on Learning for Change

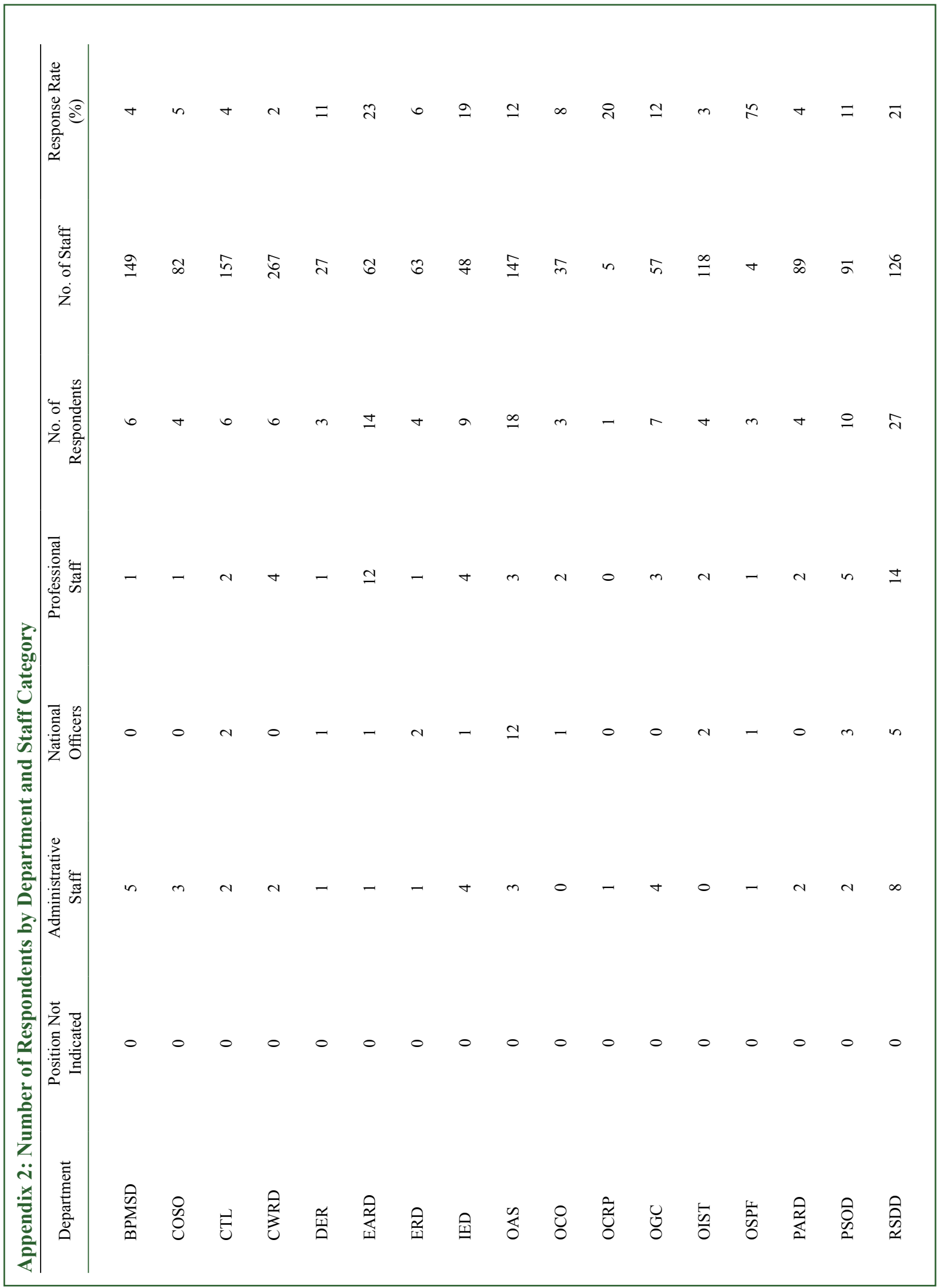




\section{Knowledge
Solutions}

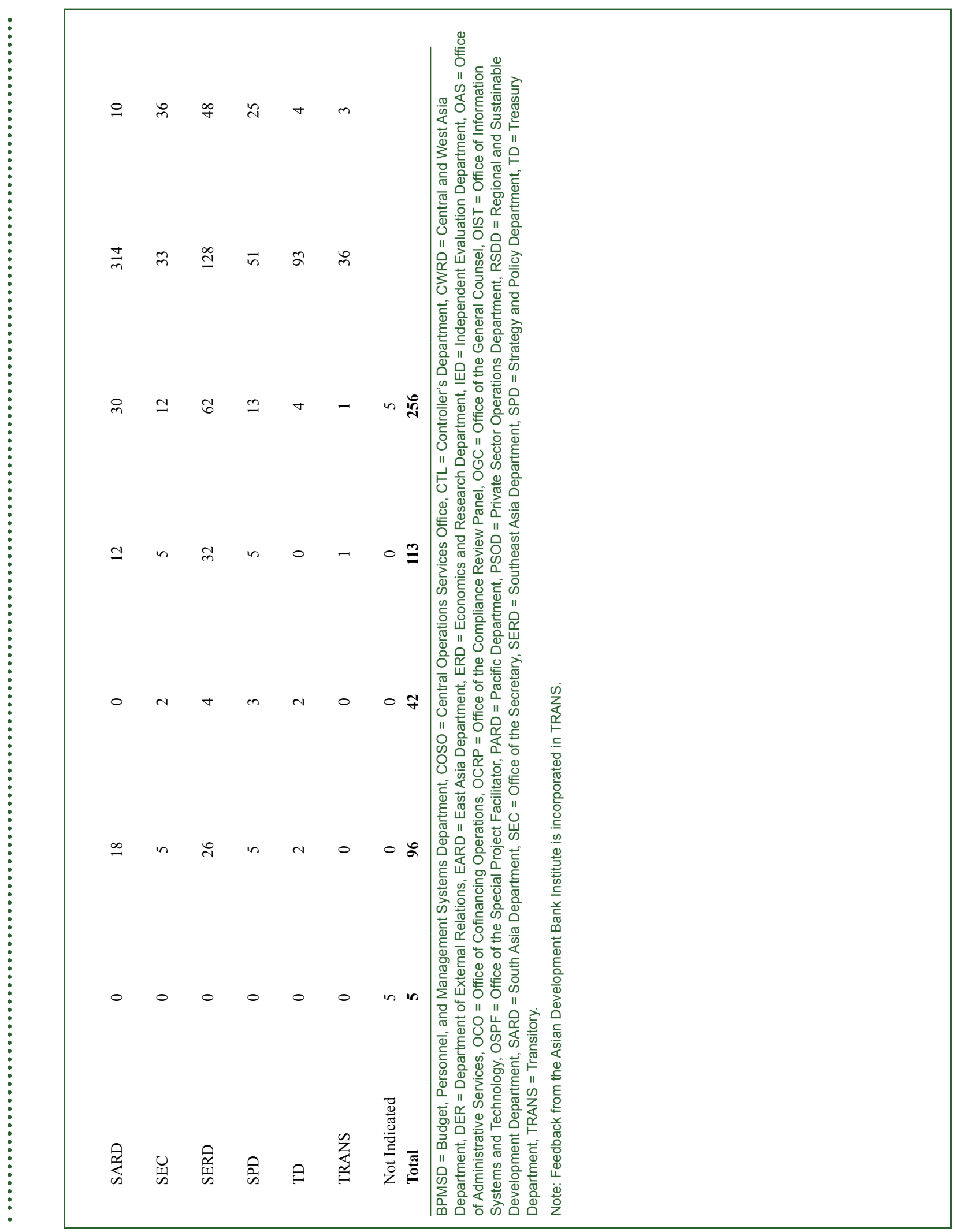




\section{Appendix 3: The Organization Subsystem}

1) There is an inspiring vision for learning and an organizational learning strategy that clearly communicates that learning is critical to organizational success.
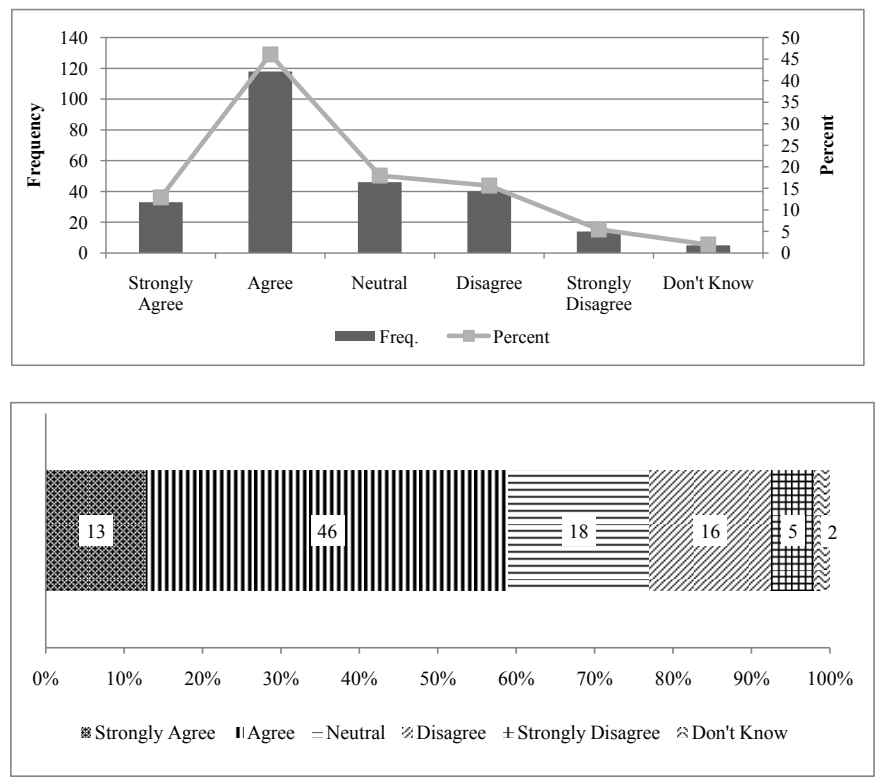

2) Leaders take an exemplary leading role in creating and sustaining a supportive learning culture.
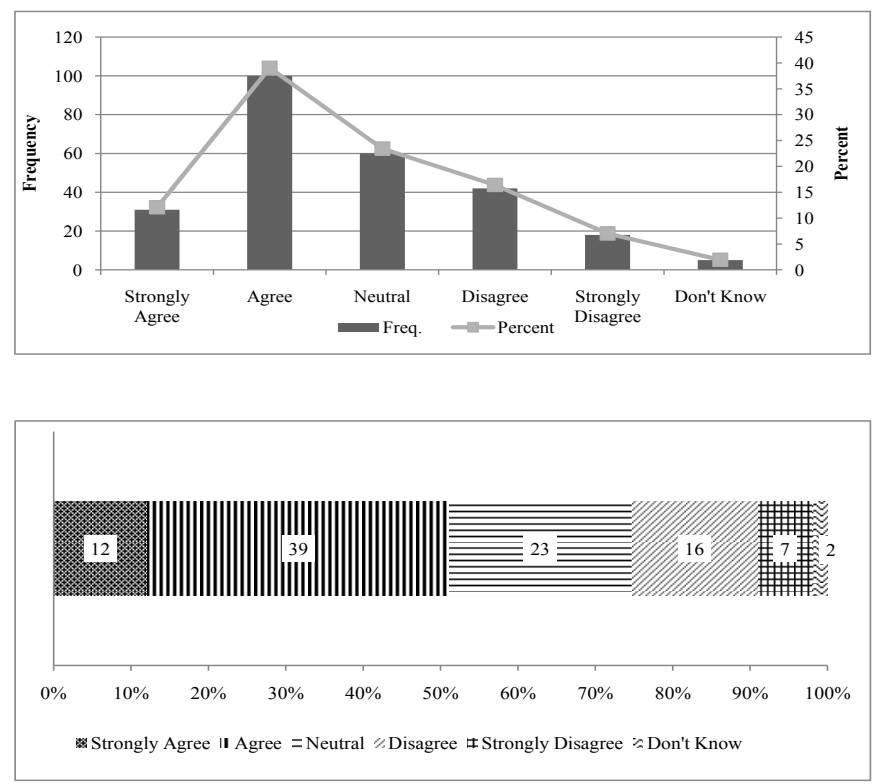
Knowledge

Solutions

3) The formal organizational structure facilitates learning, adaptation, and change.
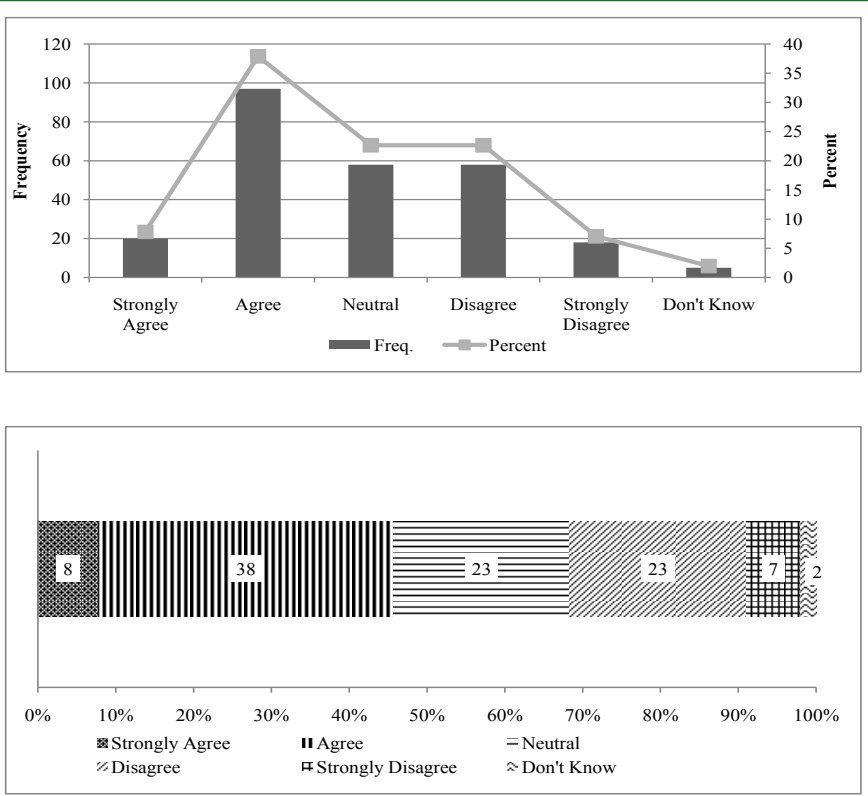

4) Sanctioned informal organizational structures enable and encourage learning across formal structural boundaries.
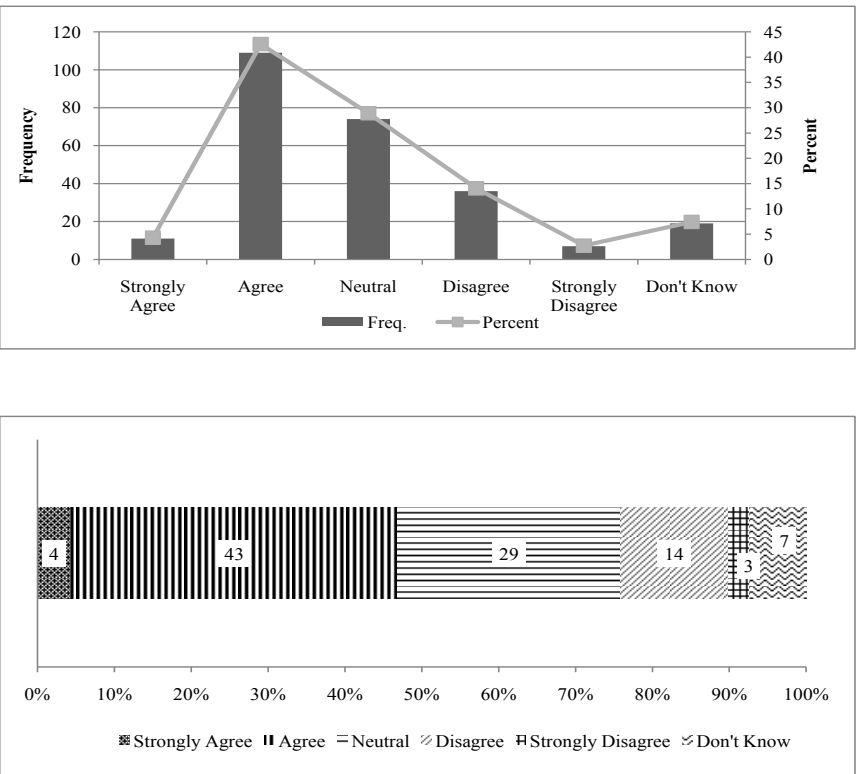
5) Good use is made of communication systems to facilitate the lateral transfer of information and knowledge and to minimize the development of "silos".

6) Adequate resources are allocated for learning in terms of time, allocation, specialist support staff, budgets for knowledge management infrastructure, formal and informal communities of practice and other value networks, and learning and development programs.
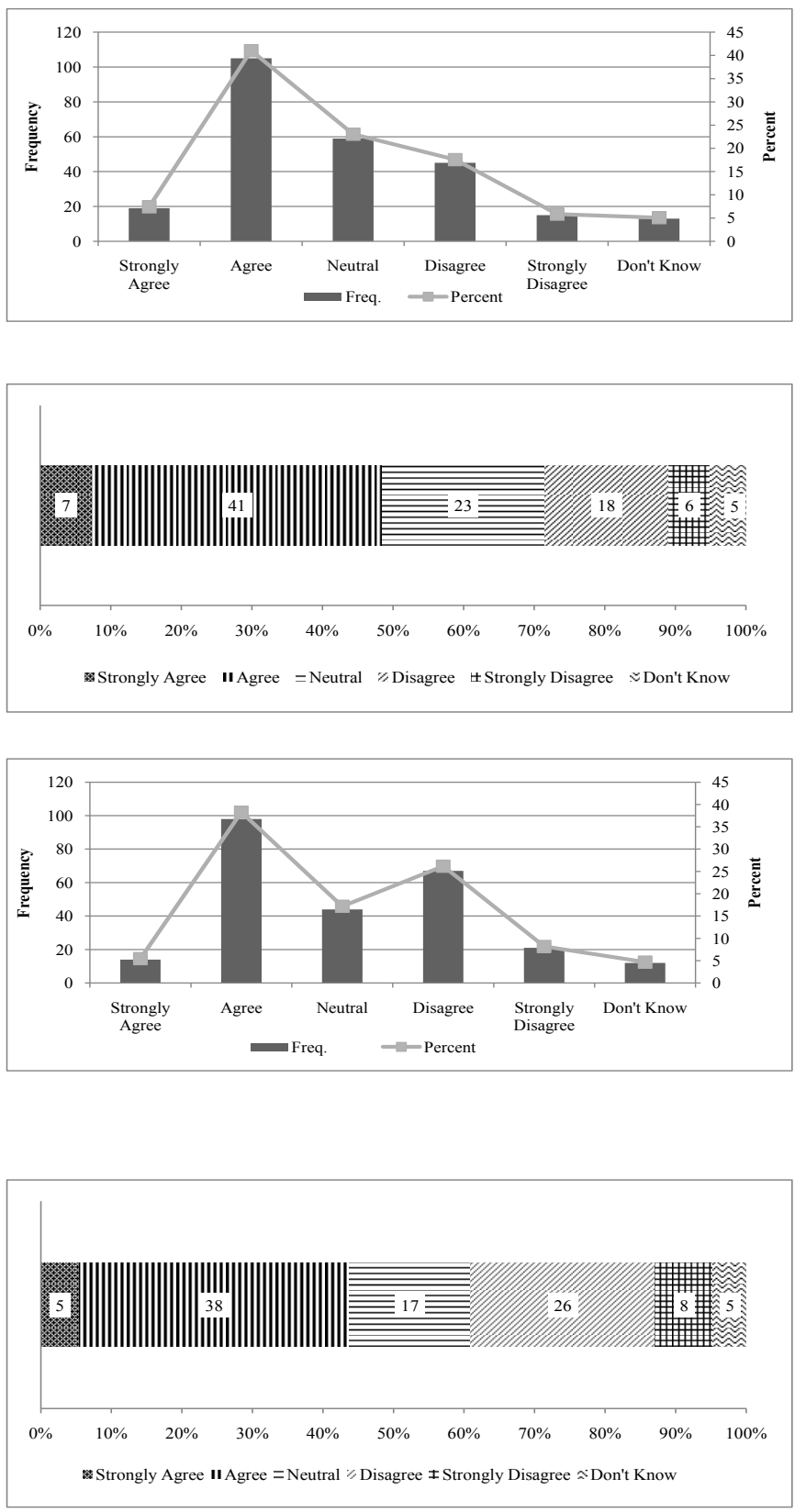
Knowledge

Solutions

7) A balanced approach to learning that recognizes the importance of both planned and emergent learning is taken.
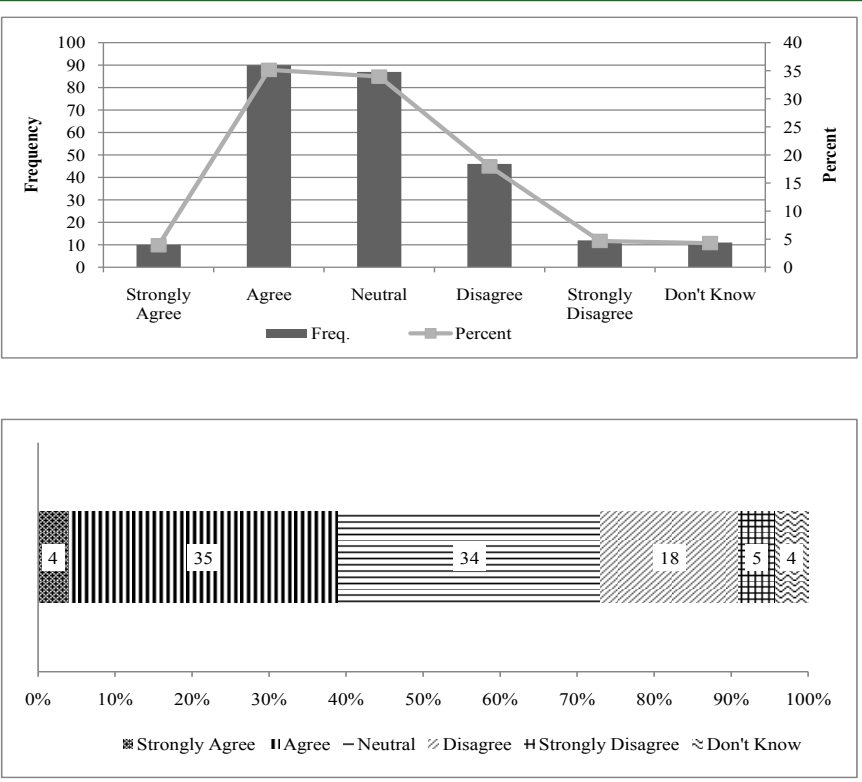

8) Planned learning is addressed through the careful design of strategy, structure, systems, procedures, and plans.
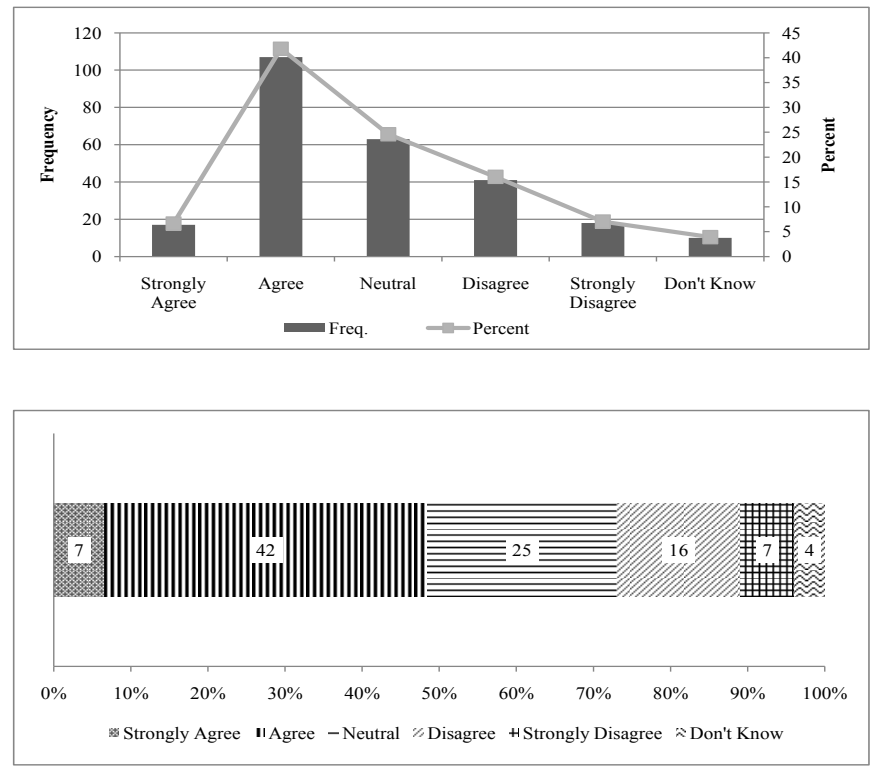
9) Emergent learning is encouraged by creating opportunities for informal sharing of knowledge and experience.

10) Failures and unintended outcomes are the focus of constructive discussions leading to new approaches. When such incidents involve clients, care is taken to protect their reputation
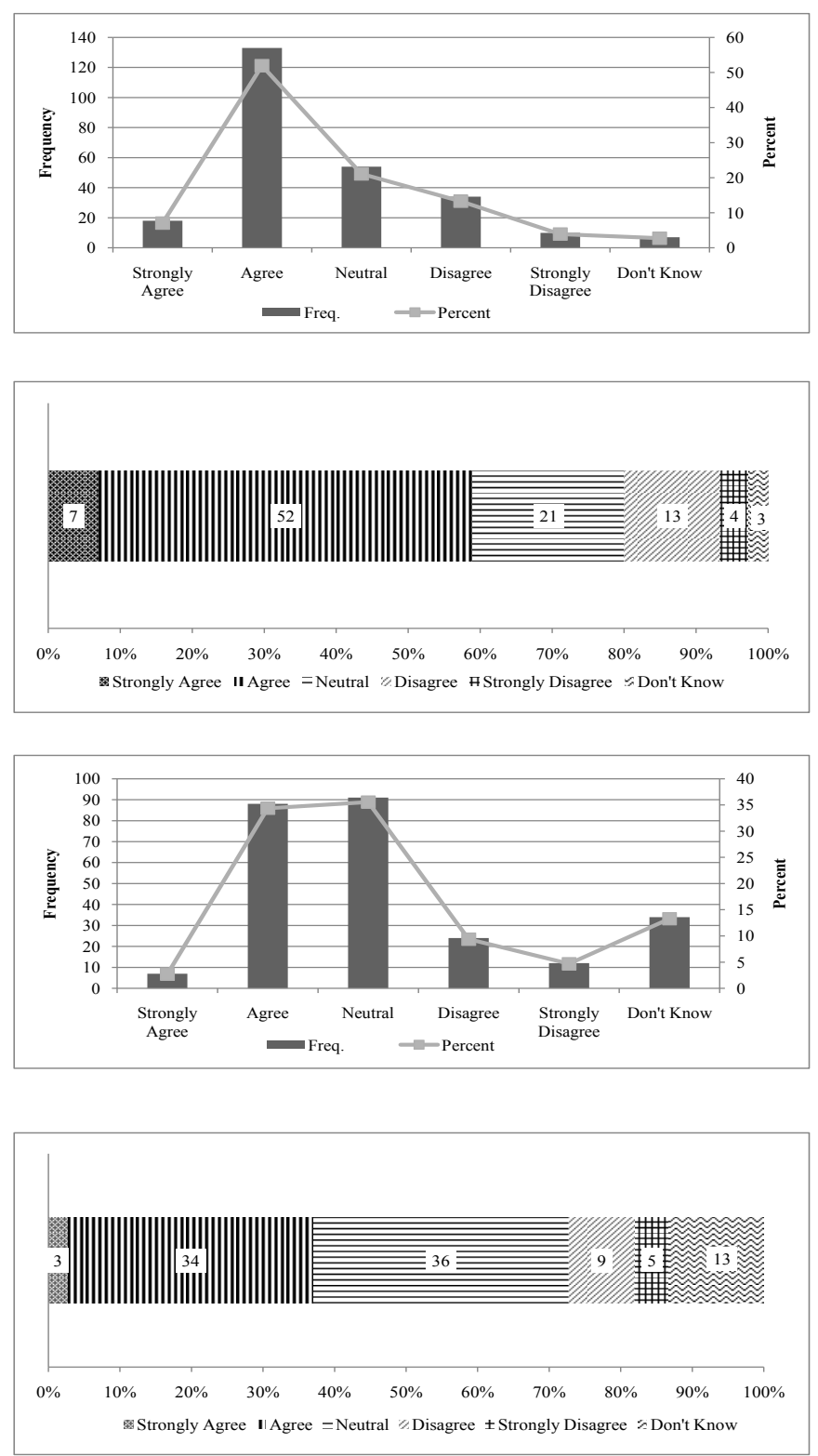


\section{Appendix 4: The People Subsystem}

1) Staff members are required to be reflective practitioners to reflect on their experience, develop experiencebased theories of change, continuously test these in practice with colleagues, and use their understanding and initiative to contribute to knowledge development
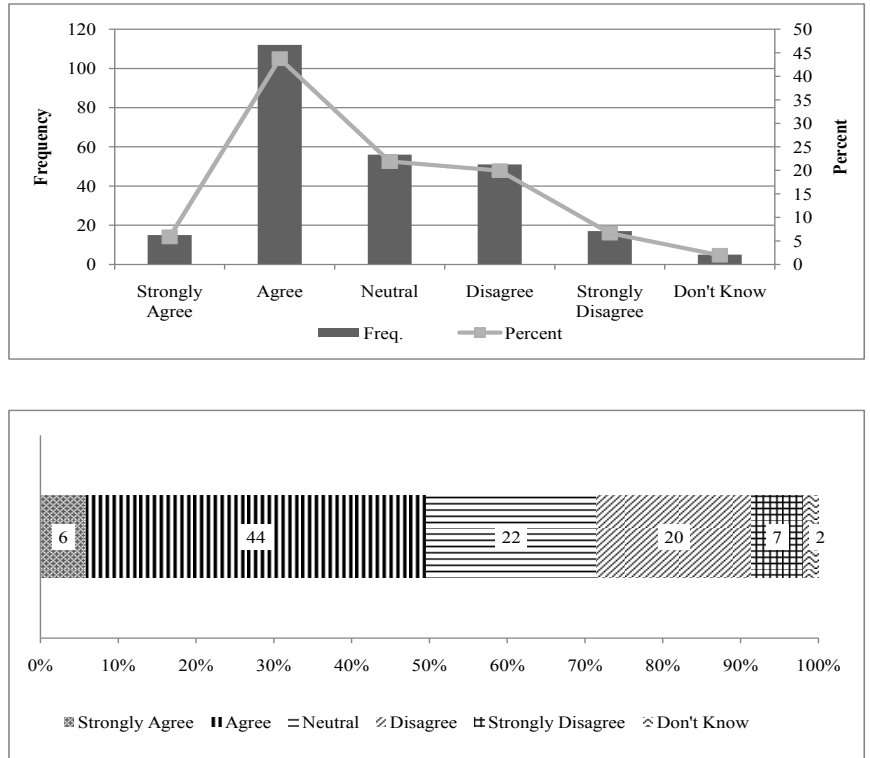

2) All staff members make frequent use of a range of tools, methods, and approaches for learning and collaborating with others.
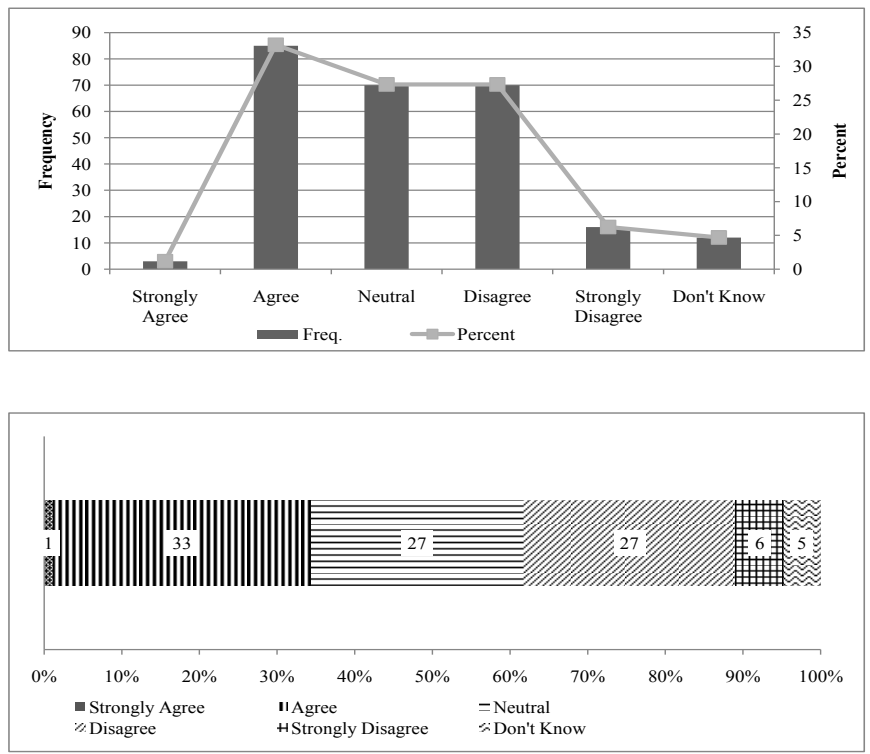
3) Staff members experience a high level of psychological safety and trust; they can rely on colleagues and are not exposed to unfair negative criticism.
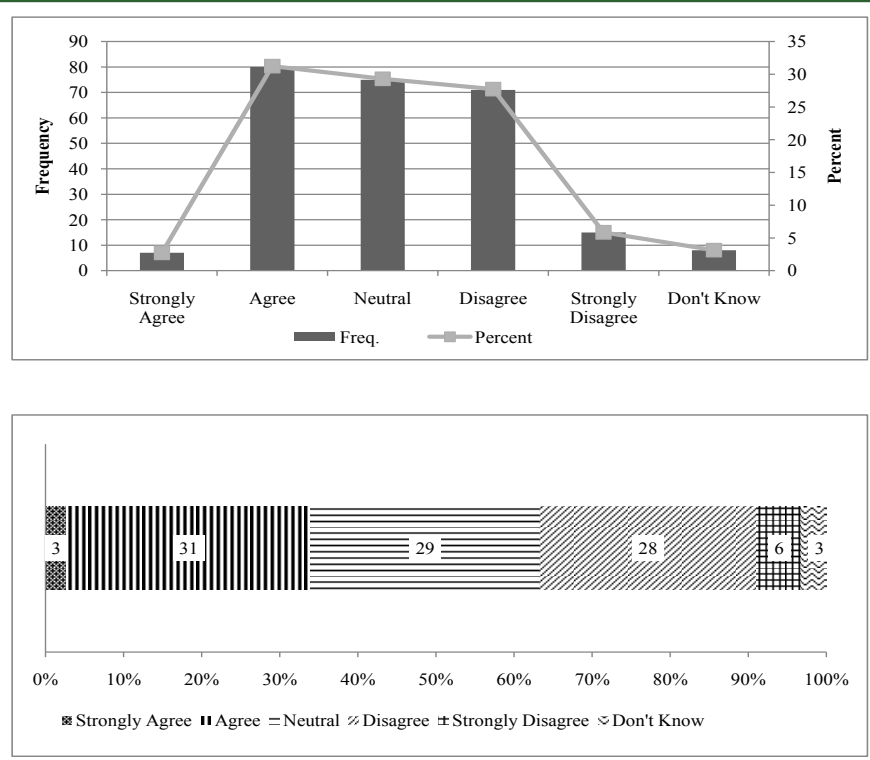

4) Teams operate as learning communities in which success and unexpected outcomes are analyzed and in which sensitively expressed dissent, conflict, and debate are encouraged as positive sources of learning.
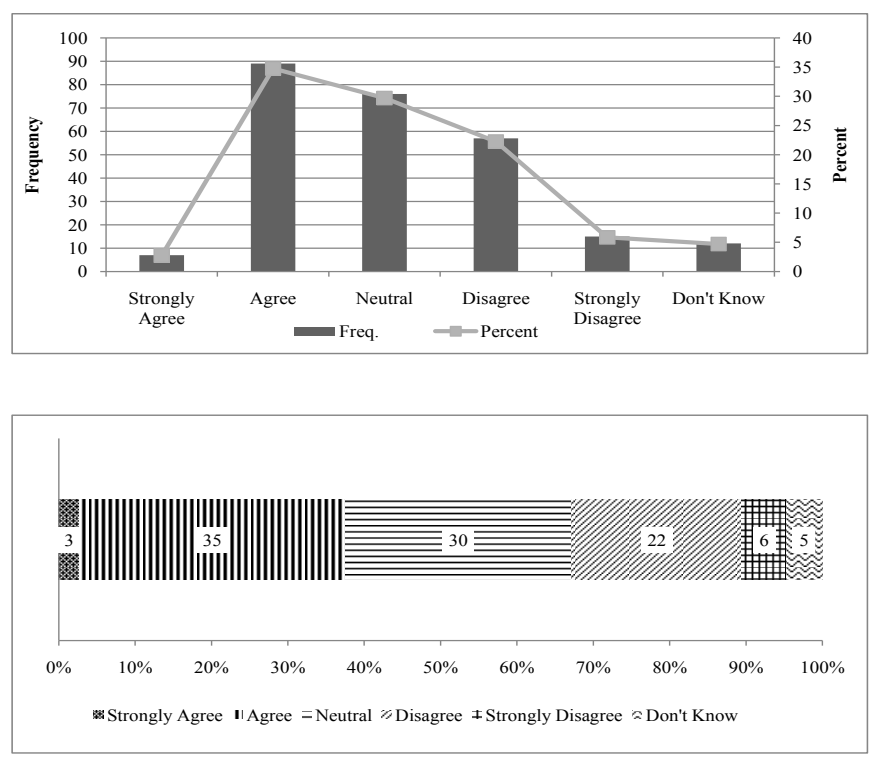

5) Staff members are encouraged to look outside the organization for new ideas, trends, and practices and to share what they learn with colleagues.

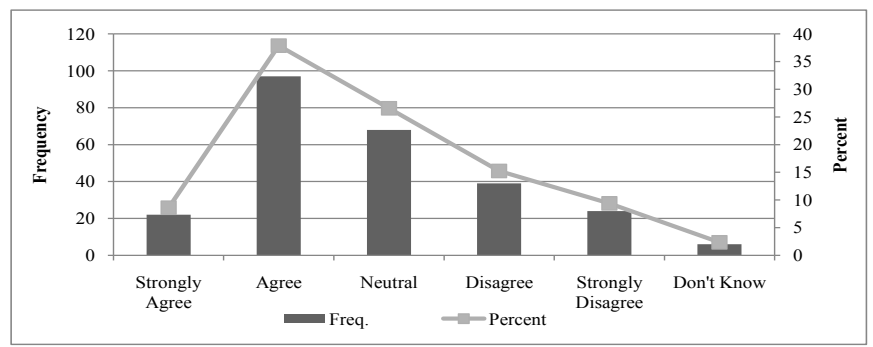


6) Equal attention is paid to developing and retaining staff members at all levels.
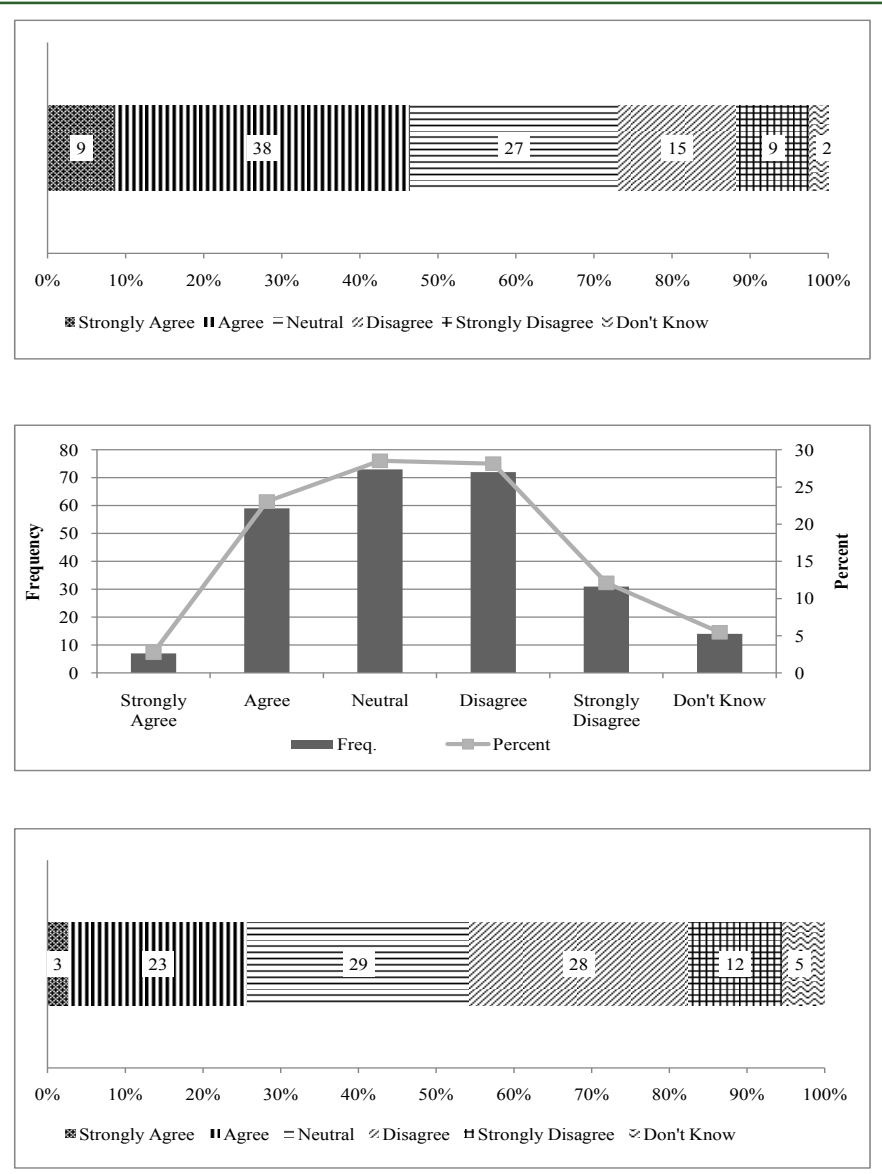

7) Staff members successfully use a wide range of opportunities for individual and team-based learning and development.
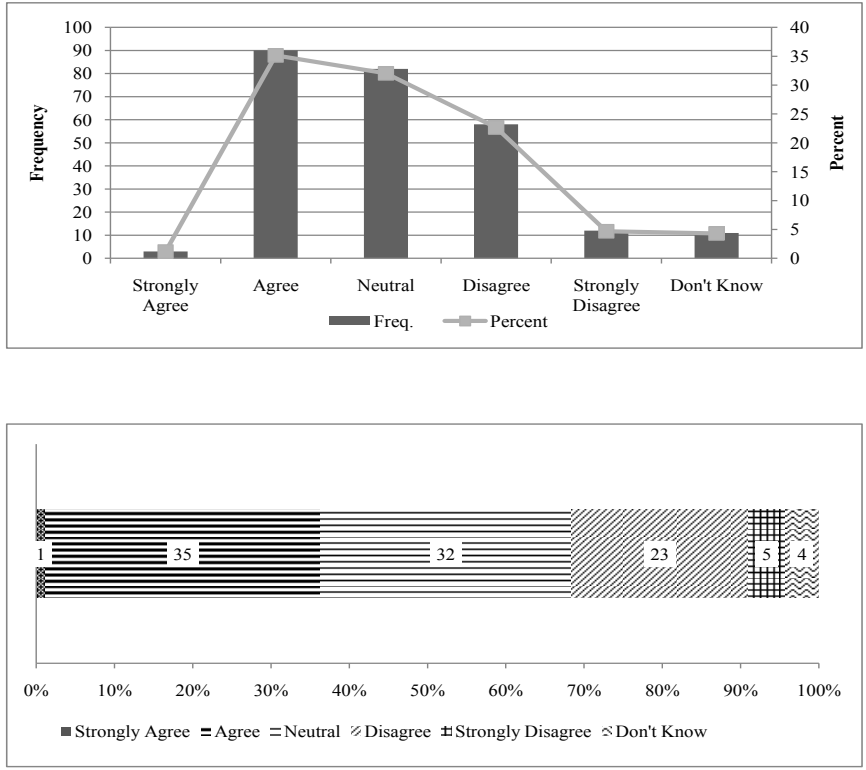
8) Time and effort spent by staff members on learning and knowledge development are recognized as core activities in the organization's time and performance management systems.
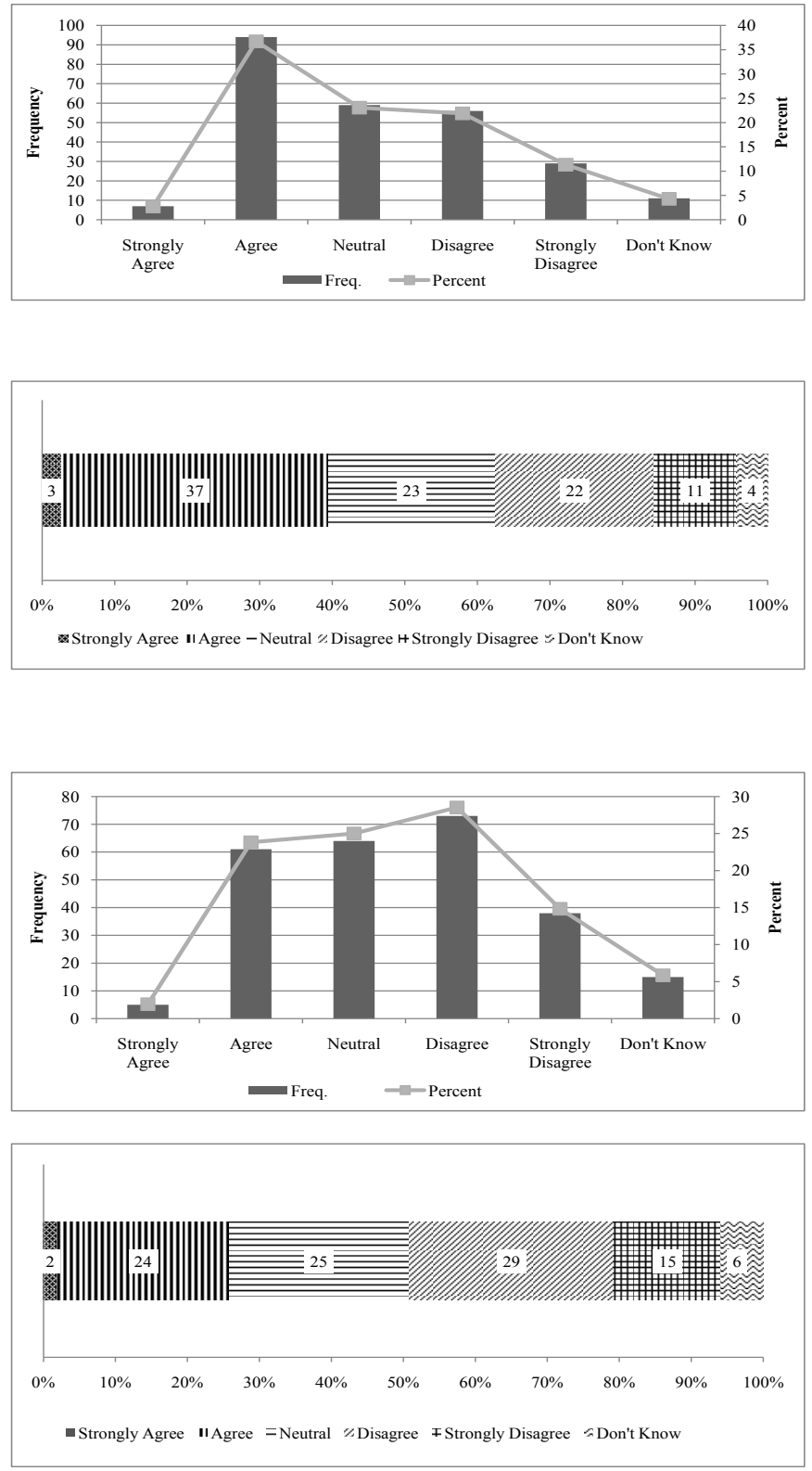

10) Leadership (based on the possession of expertise and knowledge) is expected from staff members at all levels in the organizational hierarchy.

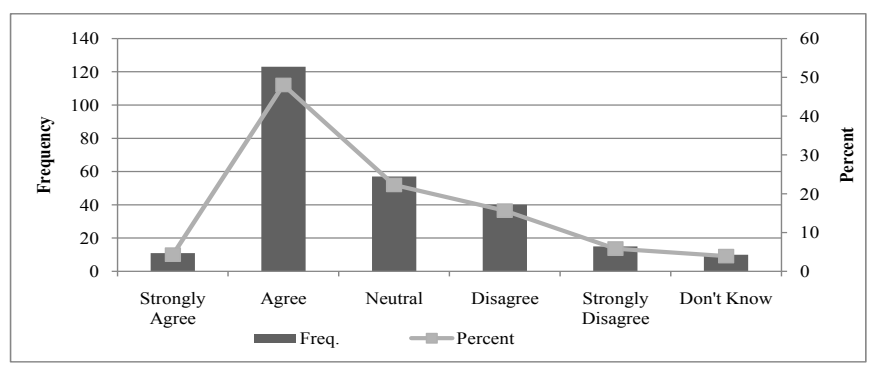




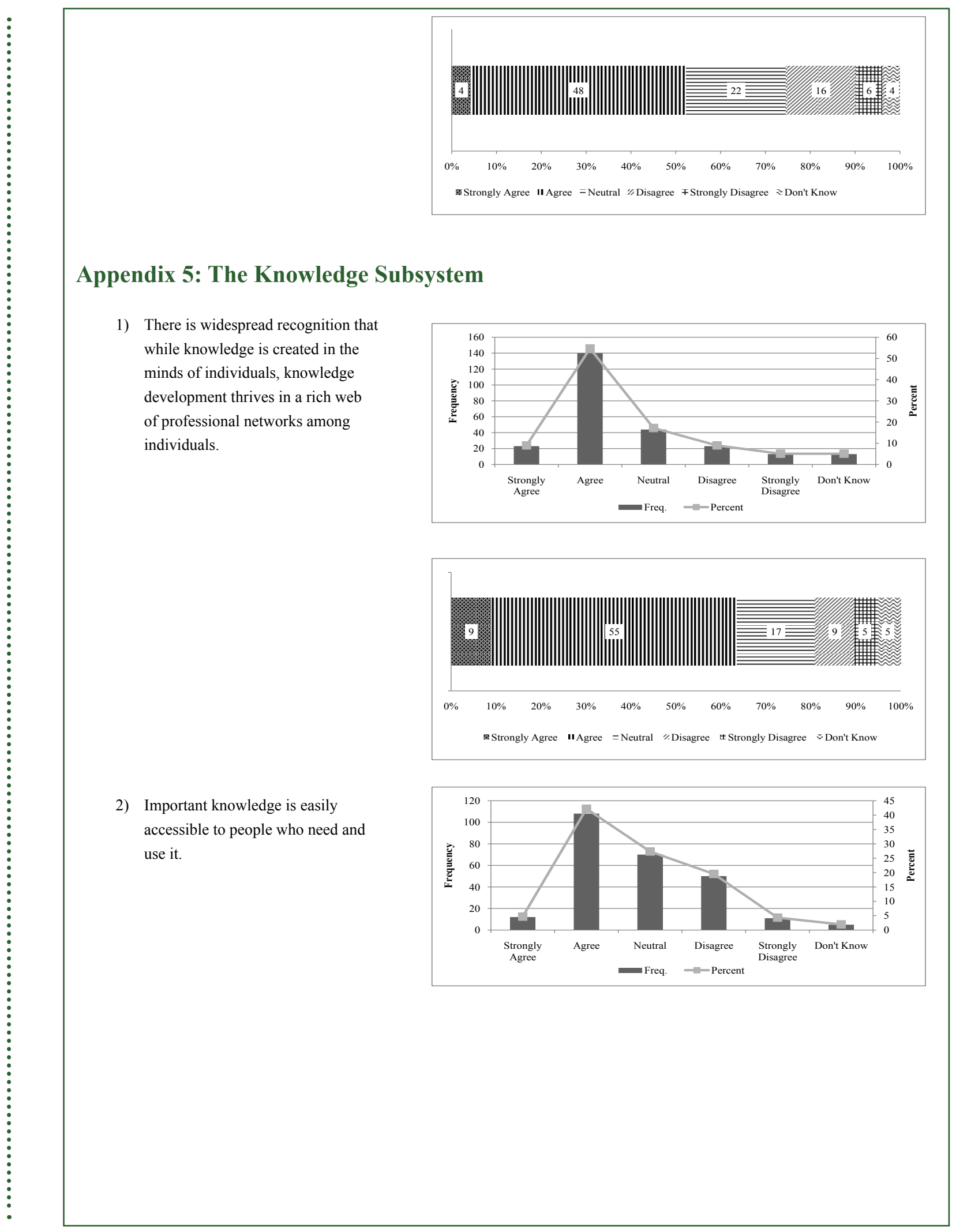


3) There are creative opportunities for knowledge to be developed and shared with others by facilitating networks between individuals.
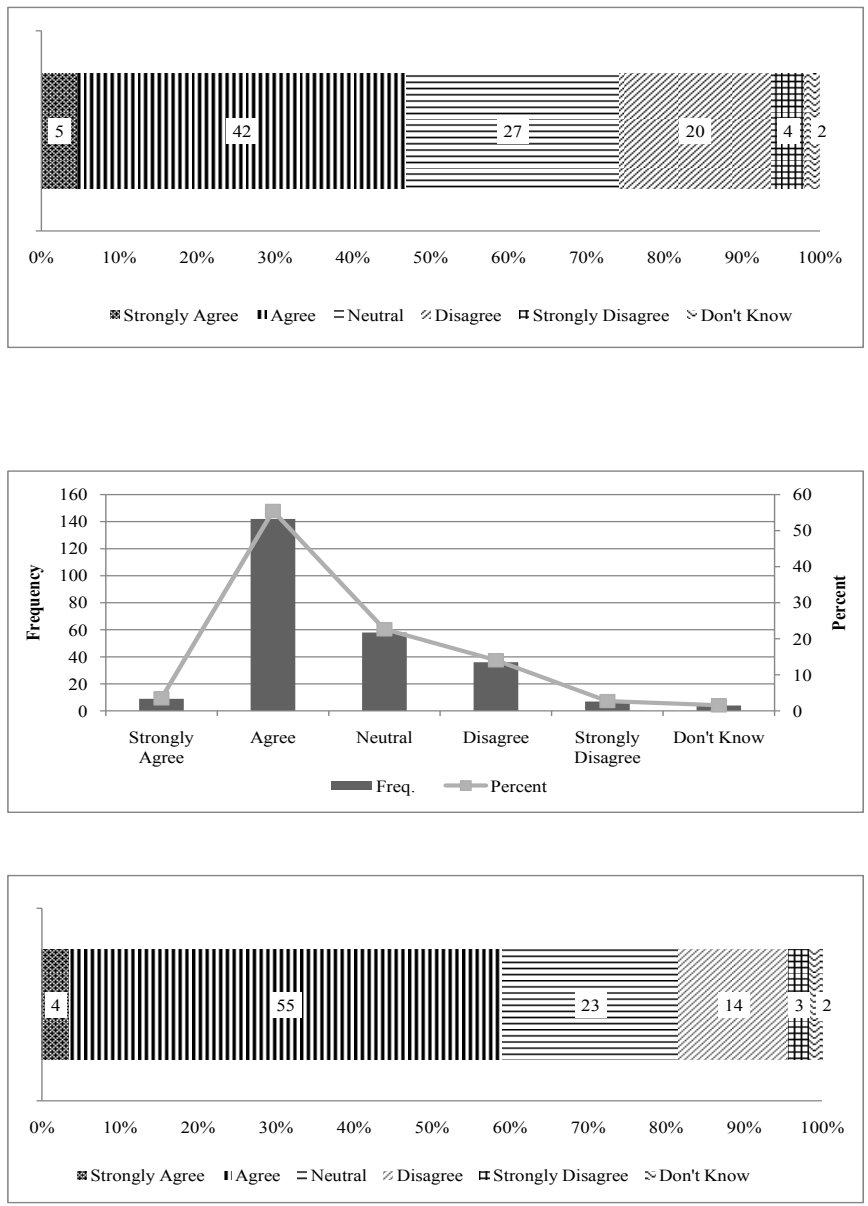

4) The design and delivery of products and services demonstrate how effective the organization is at applying what it has learned about the nature of good practice.
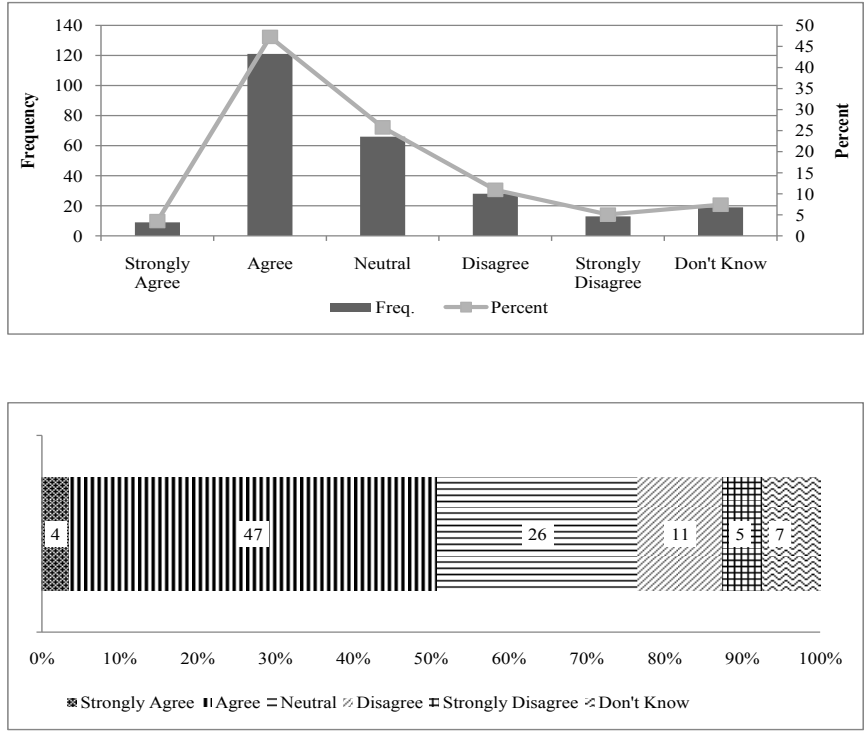
5) The necessary systems and infrastructure for knowledge management are in place, understood, and working effectively.
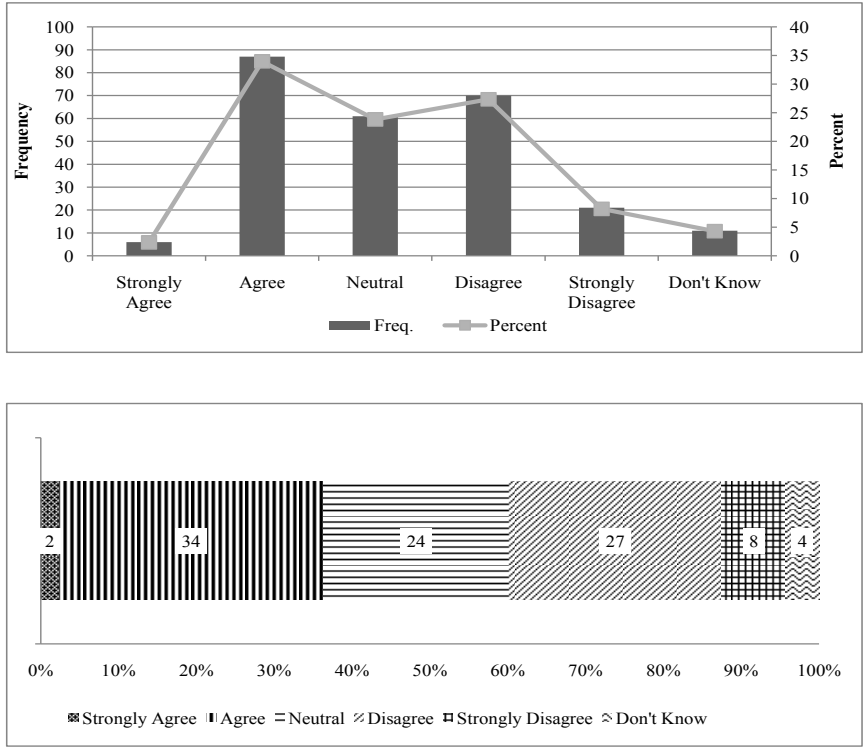

6) Evaluations are carefully designed with learning (as well as accountability) in mind. Systems ensure that the outputs of internal and independent evaluations are made widely available; carefully examined; and used to influence decision making and planning, question orthodox thinking, and trigger creativity and innovation.
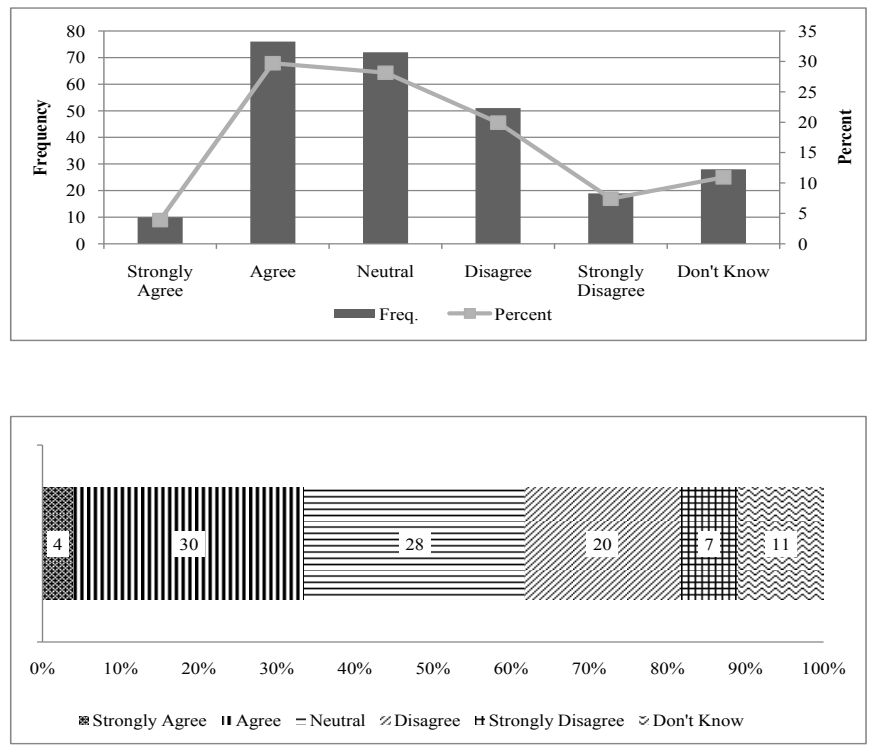

7) Peer assists, drawing on individuals' expertise and documented lessons learned, are used in planning new initiatives to reduce the likelihood of repeated and unintended negative outcomes.

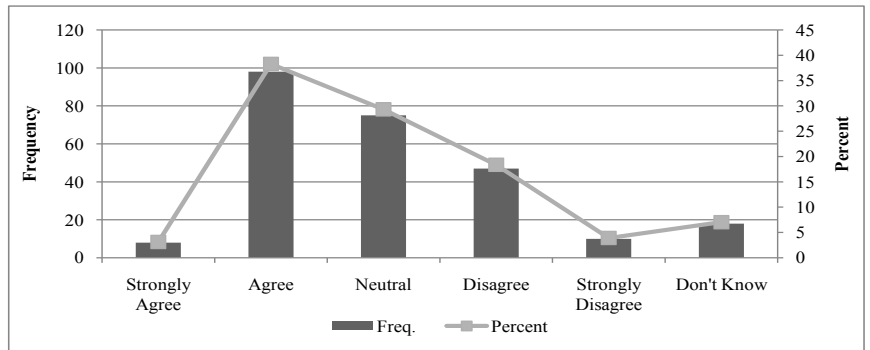


8) The organization has a resilient organizational memory and is not vulnerable to the loss of important knowledge when staff members move to other jobs in the organization or leave.
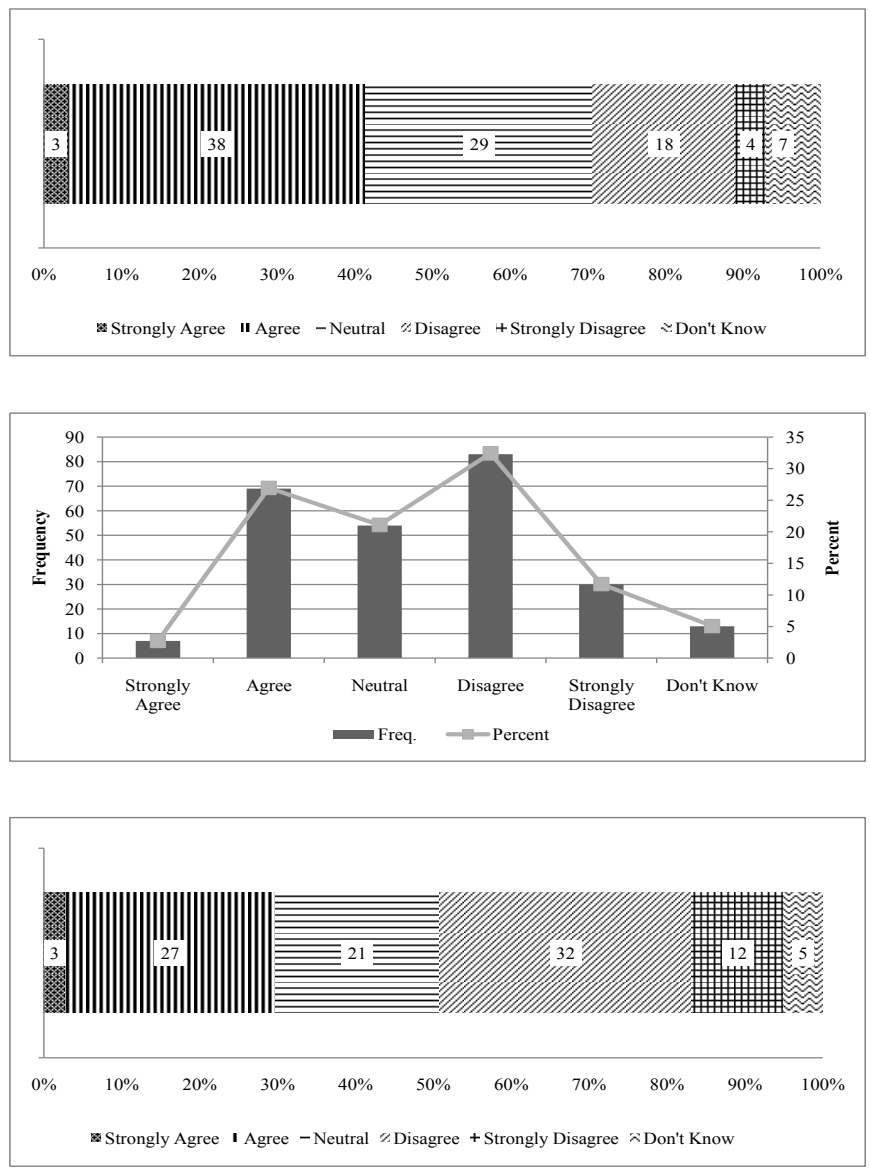

9) Individuals and teams successfully use a range of methods for surfacing their tacit knowledge and making it available to others, for example, by using carefully targeted documentation and collaborative working practices.
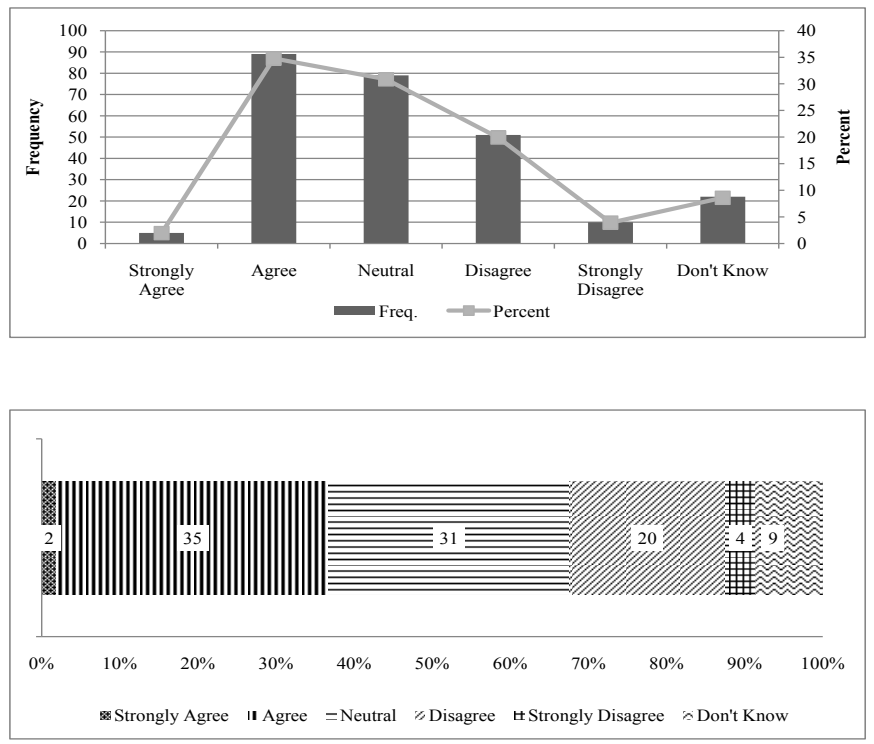
Knowledge

Solutions

10) Adoption of after-action reviews and retrospects to learn from experience has been successful.
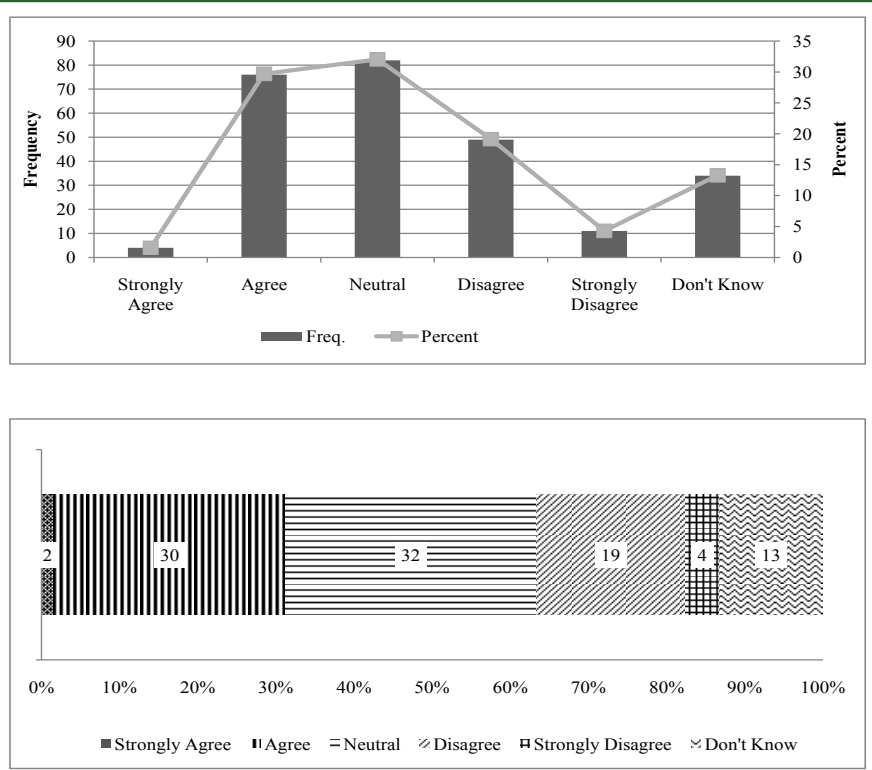

\section{Appendix 6: The Technology Subsystem}

1) There is a thorough and shared understanding of the value of information and communication technologies for knowledge management and learning.
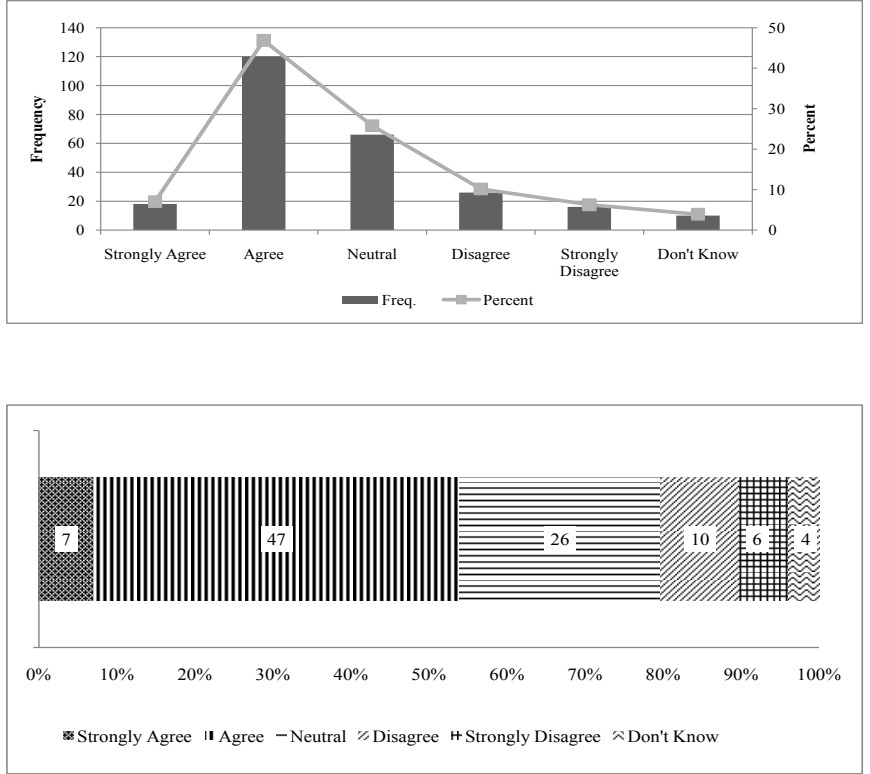
2) Information and communication technologies facilitate but do not drive or constrain knowledge management and learning in the organization.

3) Information and communication technologies are successfully used to create and sustain learning communities.
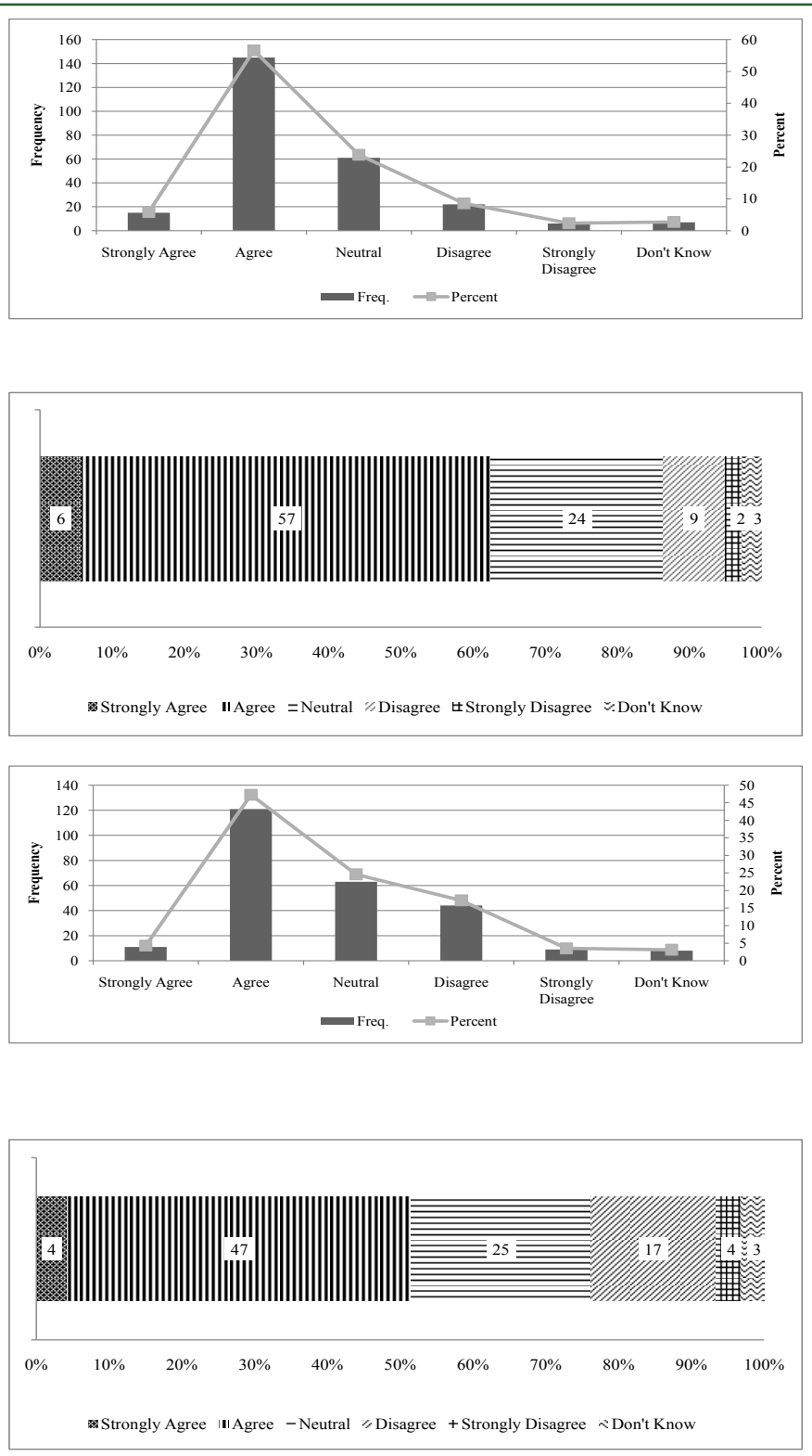

4) Information and communication technologies are successfully used to keep people informed and aware of corporate developments.

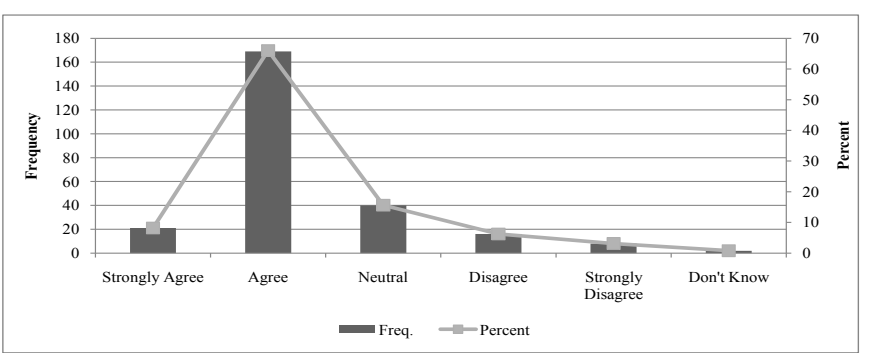


Knowledge

Solutions

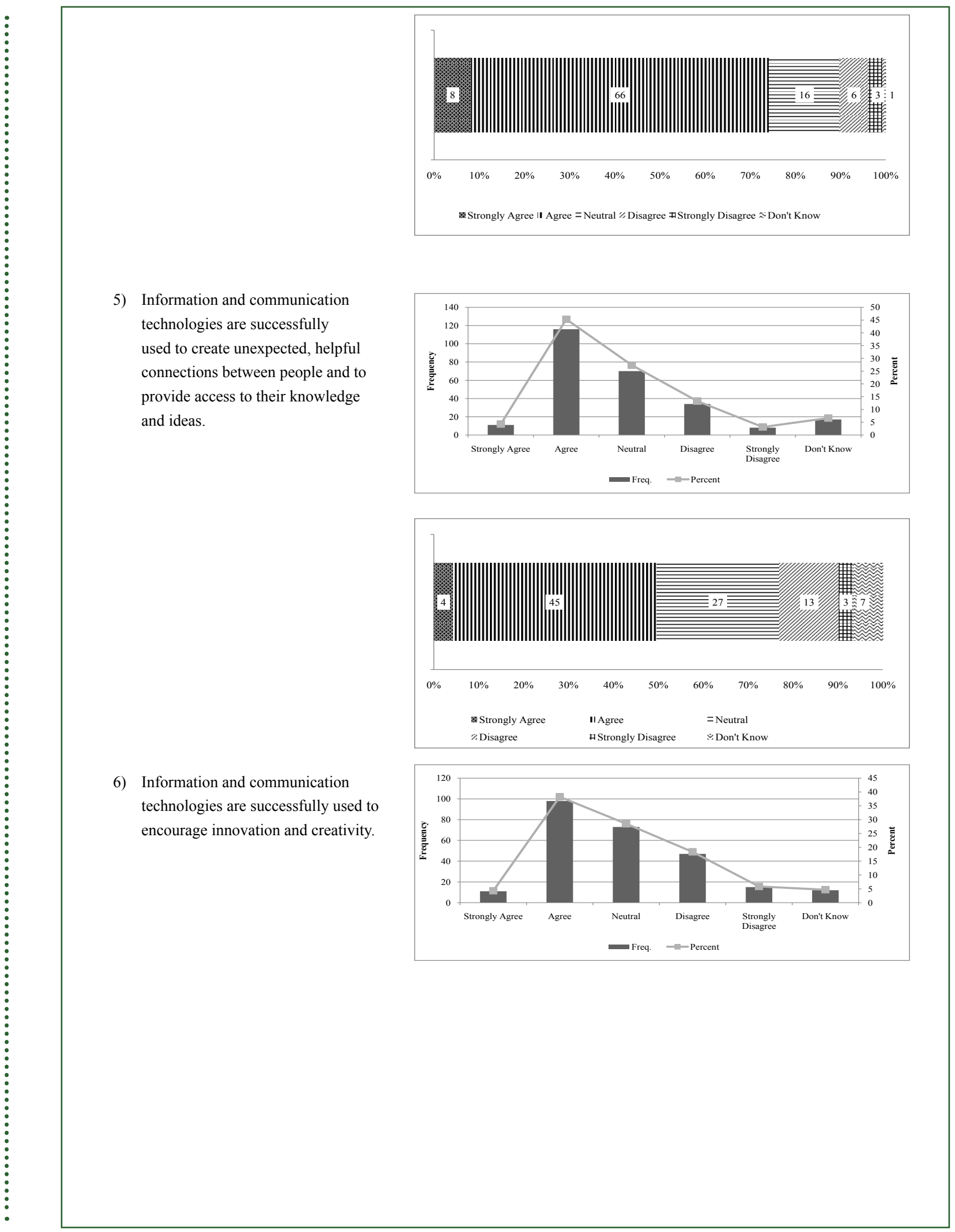


Seeking Feedback on Learning for Change

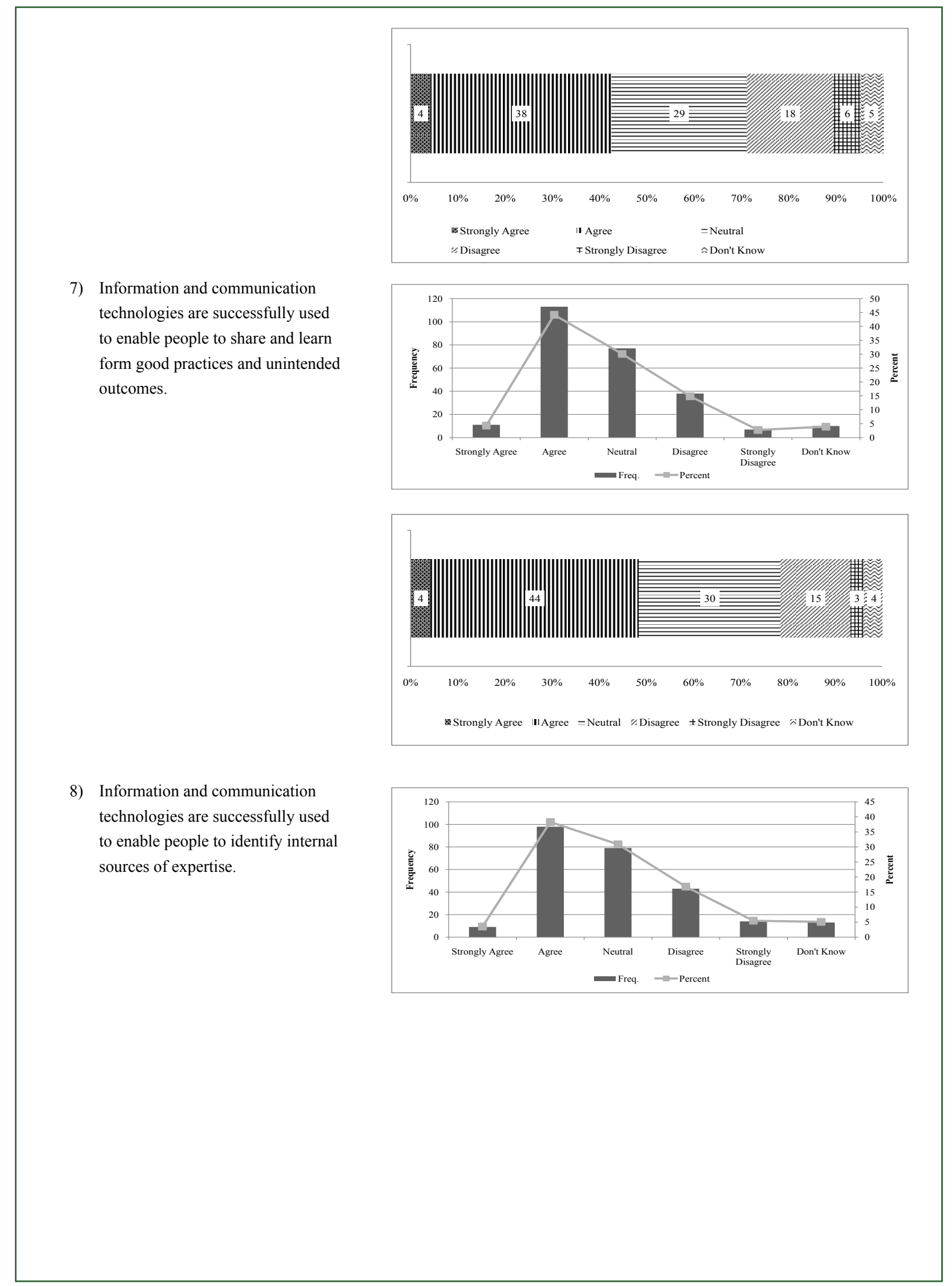


9) Creative use of information and communication technologies is high. At least five of the following have been successfully adopted: shared document drives, intranet pages, online communities and networks, wikis, and other means of collaborative document production, blogging, online storytelling, lessons learned databases, staff profile pages, online webinars, podcasts, and social network mapping.

10) Sufficient opportunities are provided for staff members to learn how to make use of available information and communication technologies for learning and sharing.
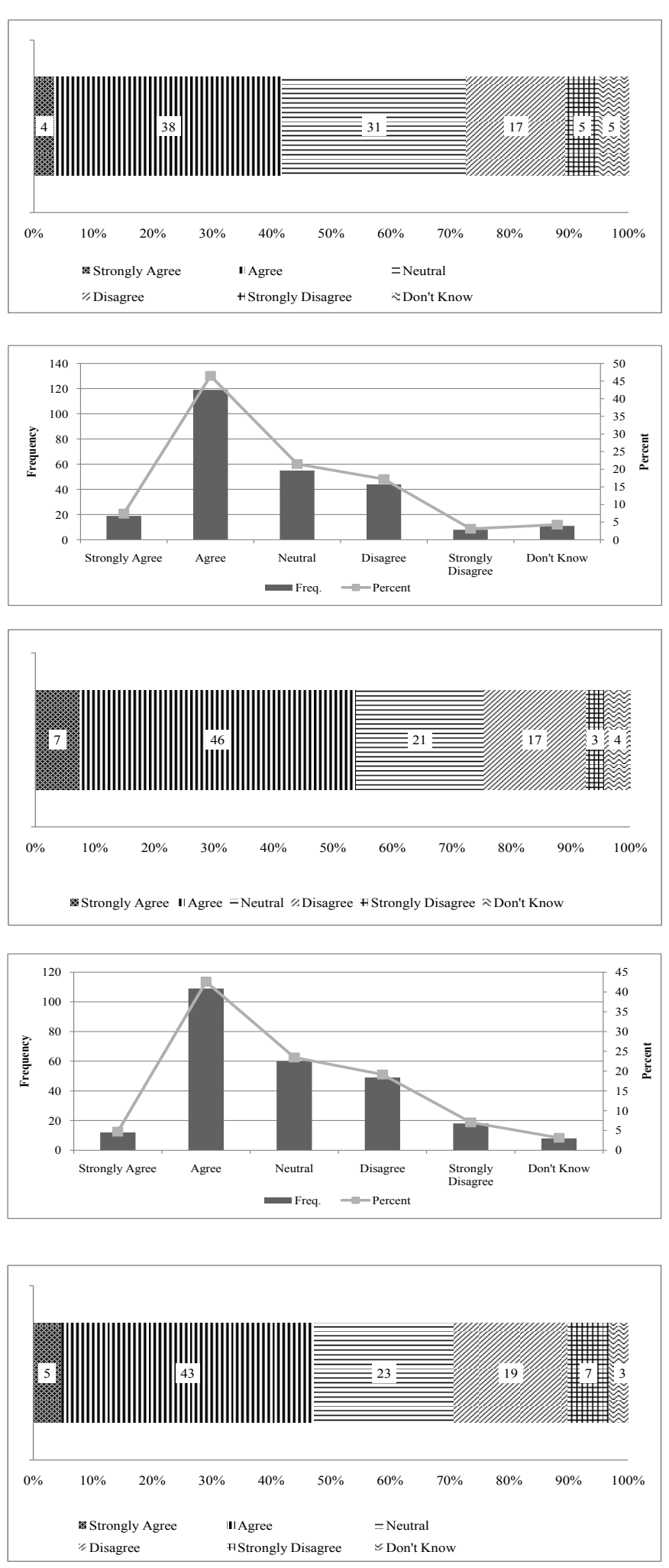


\section{Appendix 7: The People Subsystem by Staff Category}

1) Staff members are required to be reflective practitioners to reflect on their experience, develop experience-based theories of change, continuously test these in practice with colleagues, and use their understanding and initiative to contribute to knowledge development.

2) All staff members make frequent use of a range of tools, methods, and approaches for learning and collaborating with others.
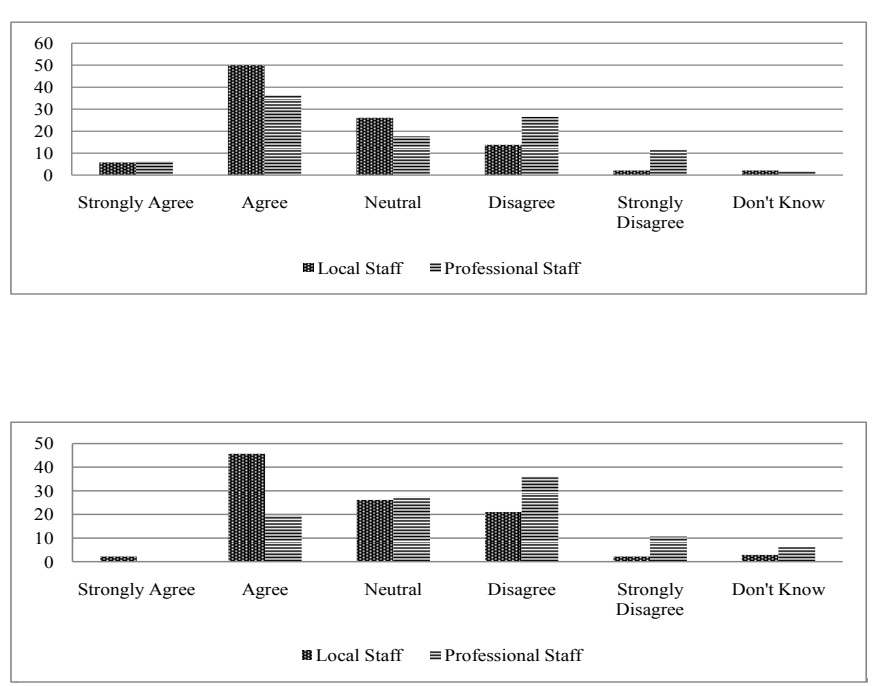

3) Staff members experience a high level of psychological safety and trust; they can rely on colleagues and are not exposed to unfair negative criticism.

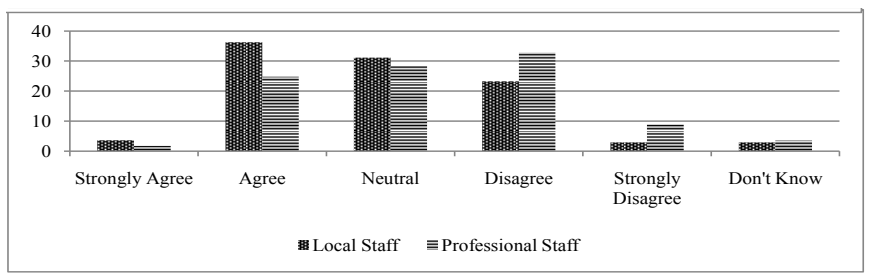

4) Teams operate as learning communities in which success and unexpected outcomes are analyzed and in which sensitively expressed dissent, conflict, and debate are encouraged as positive sources of learning.

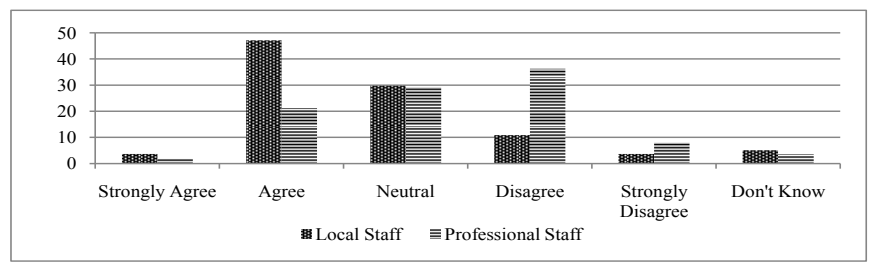


5) Staff members are encouraged to look outside the organization for new ideas, trends, and practices and to share what they learn with colleagues.

6) Equal attention is paid to developing and retaining staff members at all levels.

7) Staff members successfully use a wide range of opportunities for individual and team-based learning and development.

8) Time and effort spent by staff members on learning and knowledge development are recognized as core activities in the organization's time and performance management systems.

9) A wide range of formal and informal rewards and incentives for contributing to organizational learning and knowledge development is used (e.g., career advancement, increased income, informal peer status, additional time provided for study, and public acknowledgment for innovative contributions made).
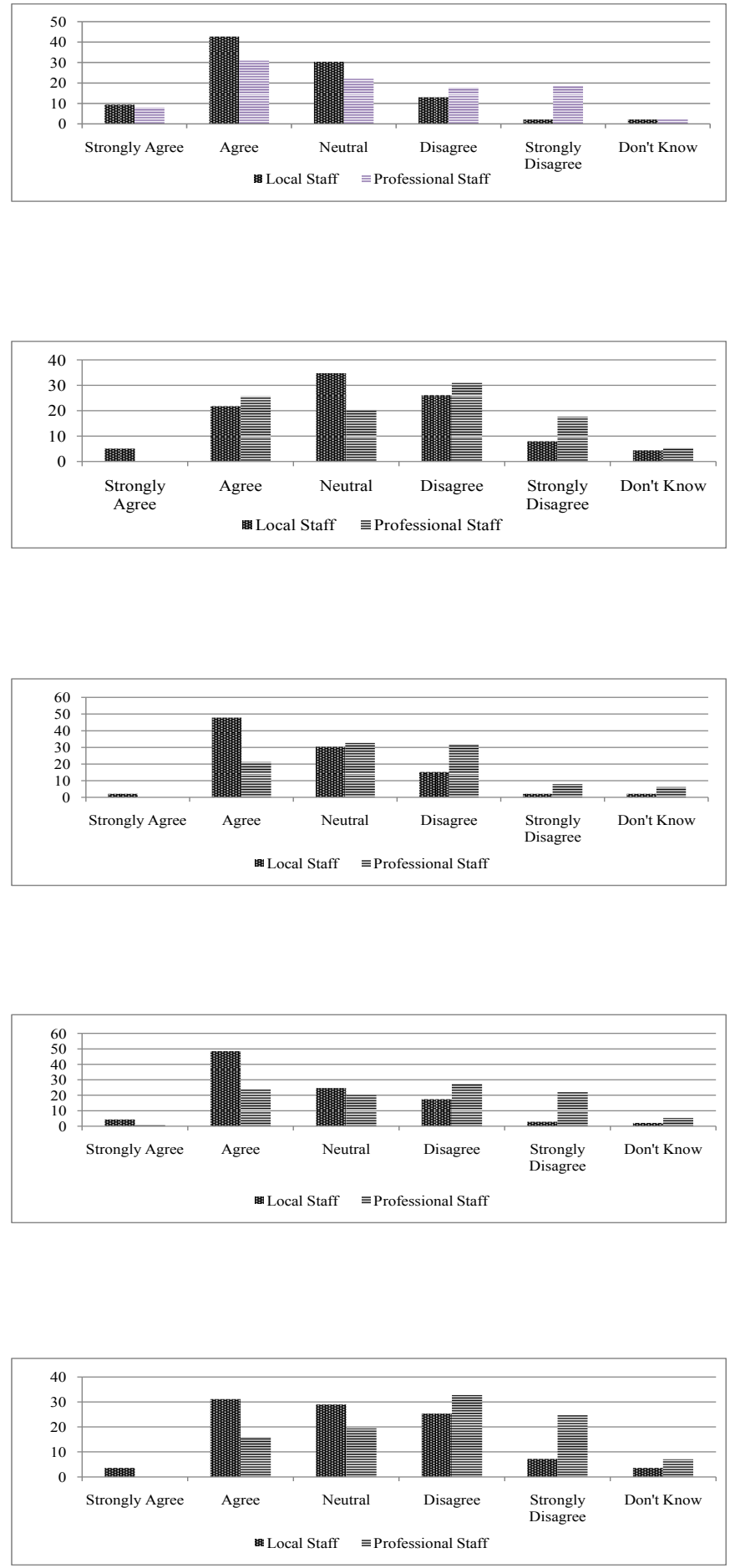
10) Leadership (based on the possession of expertise and knowledge) is expected from staff members at all levels in the organizational hierarchy.

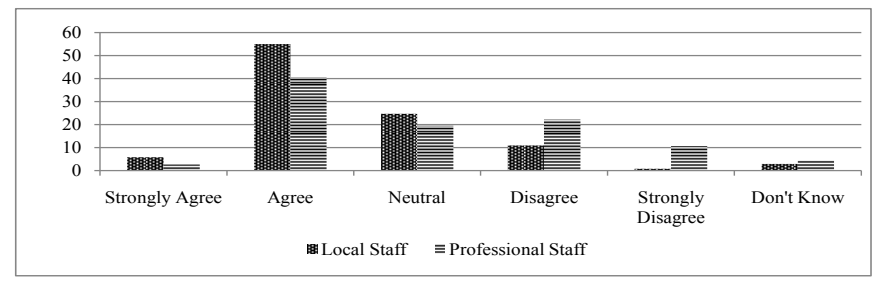

\section{Further Reading}

ADB. 2005. Perceptions of Knowledge Management. Manila. ADB. Available: www.adb.org/knowledgemanagement/assessment.asp

2009a. Enhancing Knowledge Management Strategies. Manila. Available: www.adb.org/documents/ information/knowledge-solutions/enhancing-knowledge-management-strategies.pdf

. 2009b. Learning for Change in ADB. Manila. ADB. Available: www.adb.org/documents/books/ learning-for-change/default.asp

\section{For further information}

Contact Olivier Serrat, Head of the Knowledge Management Center, Regional and Sustainable Development Department, Asian Development Bank (oserrat@adb.org). 


\section{Knowledge
Solutions}

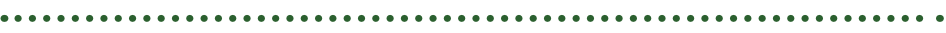

Asian Development Bank

ADB's vision is an Asia and Pacific region free of poverty. Its mission is to help its developing member countries reduce poverty and improve the quality of life of their people. Despite the region's many successes, it remains home to two thirds of the world's poor: 1.8 billion people who live on less than $\$ 2$ a day, with 903 million struggling on less than $\$ 1.25$ a day. $A D B$ is committed to reducing poverty through inclusive economic growth, environmentally sustainable growth, and regional integration.

Based in Manila, ADB is owned by 67 members, including 48 from the region. Its main instruments for helping its developing member countries are policy dialogue, loans, equity investments, guarantees, grants, and technical assistance.

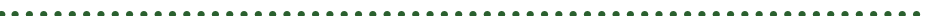

Knowledge Solutions are handy, quick reference guides to tools,

methods, and approaches that propel development forward and enhance its effects. They are offered as resources to ADB staff. They may also appeal to the development community and people having interest in knowledge and learning.

The views expressed in this publication are those of the author(s) and do not necessarily reflect the views and policies of the Asian Development Bank $(A D B)$ or its Board of Governors or the governments they represent. $A D B$ encourages printing or copying information exclusively for personal and noncommercial use with proper acknowledgment of ADB. Users are restricted from reselling, redistributing, or creating derivative works for commercial purposes without the express, written consent of ADB.

Asian Development Bank

6 ADB Avenue, Mandaluyong City

1550 Metro Manila, Philippines

Tel +6326324444

Fax +6326362444

knowledge@adb.org

www.adb.org/knowledgesolutions 